\title{
Neuroinflammation: friend and foe for ischemic stroke
}

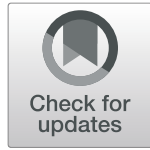

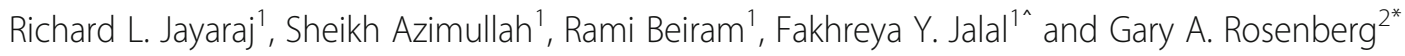

\begin{abstract}
Stroke, the third leading cause of death and disability worldwide, is undergoing a change in perspective with the emergence of new ideas on neurodegeneration. The concept that stroke is a disorder solely of blood vessels has been expanded to include the effects of a detrimental interaction between glia, neurons, vascular cells, and matrix components, which is collectively referred to as the neurovascular unit. Following the acute stroke, the majority of which are ischemic, there is secondary neuroinflammation that both promotes further injury, resulting in cell death, but conversely plays a beneficial role, by promoting recovery. The proinflammatory signals from immune mediators rapidly activate resident cells and influence infiltration of a wide range of inflammatory cells (neutrophils, monocytes/ macrophages, different subtypes of T cells, and other inflammatory cells) into the ischemic region exacerbating brain damage. In this review, we discuss how neuroinflammation has both beneficial as well as detrimental roles and recent therapeutic strategies to combat pathological responses. Here, we also focus on time-dependent entry of immune cells to the ischemic area and the impact of other pathological mediators, including oxidative stress, excitotoxicity, matrix metalloproteinases (MMPs), high-mobility group box 1 (HMGB1), arachidonic acid metabolites, mitogen-activated protein kinase (MAPK), and post-translational modifications that could potentially perpetuate ischemic brain damage after the acute injury. Understanding the time-dependent role of inflammatory factors could help in developing new diagnostic, prognostic, and therapeutic neuroprotective strategies for post-stroke inflammation.
\end{abstract}

Keywords: Stroke, Neuroinflammation, Ischemia, Blood-brain barrier

\section{Introduction}

Although stroke is the third leading cause of death after heart disease and cancer, it leads to permanent disabilities in $80 \%$ of survivors $[1,2]$. Stroke can be classified into ischemic or hemorrhagic, in which $85 \%$ of strokes are ischemic [3]. Worldwide, cerebrovascular disease and in particular stroke causes a large percentage $(47-67 \%)$ of disability-adjusted life years and death [4]. Ischemic stroke is characterized by arterial occlusion due to embolus or thrombus [5]. The functional and metabolic irregularities that occur during ischemic stroke largely depend on the artery that is occluded, which in turn determines the size of the ischemic area in the brain [6].

In 2014, a review by Mehndiratta et al. reported that there is an increase in incidence of ischemic stroke subtypes in Asian countries, since Arab countries have

\footnotetext{
* Correspondence: GRosenberg@salud.unm.edu

Deceased

${ }^{2}$ Department of Neurology, University of New Mexico Health Sciences Center, Albuquerque, NM 87131, USA

Full list of author information is available at the end of the article
}

identical epidemiological characteristics to other Asian countries, that would suggest an increase in ischemic stroke in Arab countries as well [7]. Moreover, reports from a population-based screening program indicate that there is a very high risk for cardiovascular disease, especially diabetes and obesity in the United Arab Emirates [8, 9]. These reports indicate that there will be a substantial increase in stroke burden, which results in substantial economic and societal costs [10]. Thus, understanding molecular neuroinflammatory mechanisms could significantly potentiate therapeutic development.

While the changes due to loss of glucose and oxygen, including the triggering of a series of oxidative, biochemical, and hormonal reactions culminating in microvasculature injury and blood-brain barrier (BBB) disruption, are well established, less well understood are secondary inflammatory cells and their mechanisms that in turn initiate excitotoxicity, reactive oxygen species (ROS), and nitric oxidative species (NOS), and these events will be the focus of the following discussion [11]. 


\section{Impact of inflammatory cells on stroke}

Various studies demonstrate that apart from neurons, other cells are involved in the pathogenesis of ischemia. Moreover, neuronal, glial, and vascular elements together form a functional "neurovascular unit." Following ischemic stroke, microglia and astrocytes are activated within hours, leading to the production of cytokines and chemokines [6] and resulting in infiltration of leukocytes $[12,13]$.

\section{Microglia}

Microglia, the resident innate immune cells of the brain that represent $5-20 \%$ of the glial population, are activated after ischemic stroke resulting in morphological and phenotypical changes [14]. Activated microglia act similarly to macrophages during systemic inflammation, and they have the ability to phagocytose (clearing foreign organisms and cellular debris) and produce cytokines and MMPs that can compromise BBB function [13]. Whereas, quiescent resting microglia are in a ramified state defined by a small cell soma with wide branches projecting out $[15,16]$. However, following ischemia, microglia cells are activated but the precise mechanisms are still not clear. Transient focal cerebral ischemia caused by 15 min of transient middle cerebral artery occlusion (tMCAO) in spontaneously hypertensive stroke-prone rat (SHRSP) leads to activation of microglia in the cerebral cortex of the ischemic hemisphere, and the severity of injury may be reflected in the state of microglial activation [17]. Microgliamediated neurotoxicity is augmented by the production of ROS via NADPH oxidase [18], cytokines [6], and MMPs $[13,19]$. Sun et al. demonstrated that inhibition of microglial activation by $2 \%$ isoflurane in transient focal cerebral ischemia rats (reperfusion after $90 \mathrm{~min}$ of ischemia) reduced infarct volume, attenuated apoptosis, and significantly decreased microglial activation in ischemic penumbra [20]. Microglial activation also causes secondary death in the penumbra region [21]. Various studies have reported that CD14 receptors (activated by iNOS) followed by tolllike receptor 4 (TLR4) are expressed in activated microglia in infarct brain region, and hence, this could be a possible microglial activation mechanism [22, 23]. In 2017, McDonough et al. demonstrated that sequential exposure of wild-type and TLR4 ${ }^{-/-}$microglia to hypoxia/hyperglycemia $(\mathrm{H} / \mathrm{H})$ and normoxia/normoglycemia $(\mathrm{N} / \mathrm{N})$ resulted in enhanced expression of type-1 interferon-stimulated genes (ISG) in $\mathrm{H} / \mathrm{H}-\mathrm{N} / \mathrm{N}$ wild-type microglia and not in TLR4 ${ }^{-1-}$ microglia. Type-1 interferons such as interferon- $\alpha$ and interferon- $\beta$ activate interferon- $\alpha / \beta$ receptor (IFNAR) complex and microglial type- 1 interferon-stimulated gene expression and were dependent on IFNAR1. During $\mathrm{H} / \mathrm{H}$ conditions, interferon- $\beta$ induces secretion of ISG chemokines. Enhanced expression of ISG in microglia and microglial ISG chemokine response to TLR4 agonists were dependent on IFNAR1 and TLR4. To conclude, interferon triggered gene expression in microglia plays a major role in ischemia/reperfusion injury [24]. However, during ischemic stroke, activated microglia have been shown to play a dual role, and they secrete pro-inflammatory cytokines resulting in further damage [6] and also secrete anti-inflammatory factors $[25,26]$. Three and 7 days after MCAO, edaravone, a free radical scavenger that mimics glutathione peroxidase (GPx), diminishes microglial activation and early accumulation of oxidative products in rats [27]. Similarly, multiple exposures to hyperbaric oxygen ( $\mathrm{HBO})$ reduced infarct volume by decreasing microglial activation [28]. Surprisingly, impaired microglial activation markedly increased infarct size and number of apoptotic neurons following ischemia (MCAO, $1 \mathrm{~h}$ followed by 24- or 72-h reperfusion periods) supporting the dual role of microglia [29]. Following ischemia, activated macrophages can be detected as soon as $2 \mathrm{~h}$. Between 22-46 h, both blood born and resident macrophages are dispersed over the entire lesion and stay detectable for up to 1 week in mice following the 30-min ischemic insult [30]. Microglia found around the ischemic tissue migrate towards the ischemic lesion and remain in close association with neurons for a process called "capping" (following neuron death, capping helps in early recognition and quick phagocytic removal of dead neurons) [31, 32]. Genetic deficiency of lymphocyte function-associated antigen 1 (LFA-1) abolishes the ability of microglia to migrate towards injured neurons [33]. Also, microglia play a major role in the production of growth factor TGF- $\beta 1$, which represents a neuroprotective property [34]. Recently, Jin et al. demonstrated that depletion of microglia by dual colony-stimulating factor- 1 inhibitor, PLX3397 intensifies brain infarction and neurodeficits. At day 1 and 3 after 60-min transient MCAO and reperfusion, microglia depletion also exacerbates leukocyte infiltration, expression of inflammatory mediators, and neuronal death in mice. This pathological mechanism is not only solely dependent on lymphocytes and monocytes but also due to astrocyte-mediated inflammatory factors. Hence, the presence of microglia prevented the secretion of astrocyte-mediated inflammatory factors during ischemia [35]. Also, supporting this, microglia produce various neurotrophic factors which promote neurogenesis and plasticity [36]. Hence, following ischemia, different subsets of microglia have different roles.

\section{Astrocytes}

Similar to microglia, astrocytes are housekeeping cells mandatory for maintenance of the central nervous system. They are actively involved in controlling ion and water homeostasis, releasing of neurotrophic factors, and scavenging transmitters released during synaptic activity, shuttle metabolite, and waste products and are involved in BBB formation [37]. Under normal physiological conditions, astrocytes take up excessive glutamate from 
extracellular space and convert it to glutamine for neuronal reuse, but during brain injury, the extent of damage to astrocyte might affect the ability of its glutamate uptake [37]. However, it is not clear on how ischemia exactly affects astrocytic glutamate uptake but it has been reported that the expression of glutamate transporter EAAT2 is defective during ischemia [38, 39]. Following ischemia, cytokines from neurons and glial cells lead to astrocyte reactivity hyperplasia. Astrocyte proliferation results in expression of inflammatory factors such as monocyte chemotactic protein-1, IL-1 $\beta$ [40], glial fibrillary acidic protein (GFAP), vimentin, and nestin that can lead to reactive gliosis and scar formation [41]. After stroke, due to failure of $\mathrm{Na}^{+}, \mathrm{K}^{+}$pump, astrocytes swell, which leads to high intracerebral pressure and less cerebral perfusion [42]. Reactive astrocytes release matrix metalloproteinase 2 that causes degradation of matrix protein [43]. Reactive astrocytes also cause inhibitory condition by inducing ephrin-A5 at the lesion center disturbing axonal sprouting [44]. Following photothrombotic ischemic insult in rats, extensive astroglial response is initiated in the lesions' core from $4 \mathrm{~h}$ to 1 day and reaches maximum at 4 days and persists until 28 days after onset [45]. Three days after transient global ischemia ( $10 \mathrm{~min}$ followed by reperfusion), there is a significant upregulation in the expression of iNOS, NADPH diaphorase, and GFAP in hippocampal astrocytes [46]. Post-mortem brain tissues from ischemic patients who died 3-7 days after stroke revealed an enhanced expression of IL-15 in astrocytes. Alternatively, knockdown of IL-15 in astrocytes diminished ischemic brain injury in mice subjected to transient MCAO for 60 min [47]. GFAP promoter-controlled IL-15 expressing transgenic mice showed enlarged brain infarcts, exacerbated neuronal deficits following rose bengal induced cerebral cortical photothrombotic ischemia. Additionally, GFAP/Vimentin double knockout mice showed enhanced cortical cerebral blood flow reduction and larger lesions after focal ischemia [48]. Thus, protection of non-reactive astrocytes provides significant nutrient and physical support for the survival of neurons. Calcineurin inhibitor FK506 and immunosuppressive drugs have been reported to prevent glutamate-mediated astrocyte death [49]. In addition, NF-kB inhibition in astrocytes protects neurons against 60-min ischemic injury in mice [50]. Astrocytes release brain-derived neurotrophic factor (BDNF), fibroblast growth factor-2, and nerve growth factor (NGF) that play an important role in neuroprotection $[48,51]$. In addition to neurotrophic support, structurally, astrocytes through their endfeet possess strong association with brain capillary endothelial cells and pericytes that form BBB. During ischemia, MMP-9 disrupts the connection between astrocyte endfeet and endothelial cells by degrading basal lamina [52]. Hence, ruptured BBB acts as a major gateway for the invasion of peripheral inflammatory cells.

\section{Endothelial cells and blood-brain barrier}

Endothelial cells (EC) are one of the components of the neurovascular unit. They have tight junction proteins that are the major interface with the blood. The ECs are surrounded by basal lamina, which is made up of laminin, type IV collagen, fibronectin, heparin sulfate, and other extracellular molecules (Fig. 1). Pericytes are macrophage-like cells with smooth muscle properties that are contiguous with basal lamina and are involved in both angiogenesis and in injury [53]. Pericytes also play a major role in controlling neurovascular unit physiology by regulating microvascular stability, tight junction proteins, and microvessel diameter. In addition to its role in protecting the neuronal microenvironment by preventing entry into brain of potentially toxic activated plasma proteases, the BBB has specific transport systems that supply essential nutrients [54]. Following ischemic stroke, pericytes respond quickly that may either be protective or detrimental, such as detachment, constriction, and migration from microvessel walls and cell death [55]. One hour after MCAO, pericytes migrate from the basement membrane which leads to BBB permeability [56]. In addition, proinflammatory factors enhanced the expression of chemokines, interleukins, and cellular adhesion molecules in pericyte-fibroblast co-cultures $[57,58]$. On the contrary, 7 days after ischemic stroke in mice, pericytes were reported to accumulate in the peri-infarct area which might support vascular repair, and additionally, they are able to differentiate into neural and vascular lineage cell [59]. Surprisingly, pericytes isolated from human stroke brain tissue are found to highly express microglial markers that may serve as stem cells generating microglia for phagocytic activity $[60,61]$. Although pericytes play a major regulatory role, endothelial cells and their tight junctions provide the ultimate barrier. The endothelial cells are interconnected via clefts made up of tight junction proteins (TJP), namely occludins and claudins, which act as a major barrier between interstitial fluid and blood. Following ischemia, dynamic changes in BBB permeability results in endothelial swelling, astrocyte detachment, pericyte detachment, pericyte contraction, microglial activation, vasoconstriction, and blood vessel rupture (Fig. 1). Subtle changes in BBB permeability result in endothelial hyperpermeability to macromolecules in the peri-infarct area [62]. A biphasic pattern occurs during transient $\mathrm{BBB}$ disruption where on initial opening occurs $2-3 \mathrm{~h}$ following onset and after reperfusion (24-48 h), a second opening occurs resulting in increased intracranial pressure and vasogenic edema in mice [63, 64]. This leads to the production of adhesion molecules and proinflammatory cytokines, which, in turn, aggravates the process [65]. Moreover, 24-48 $\mathrm{h}$ following 2 $\mathrm{h}$ of MCAO with reperfusion in rats, MMPs activate microglia, macrophage, and neutrophils which secrete additional MMPs further compromising cerebral vessels [53]. However, therapeutic approaches, such as agents that induce 


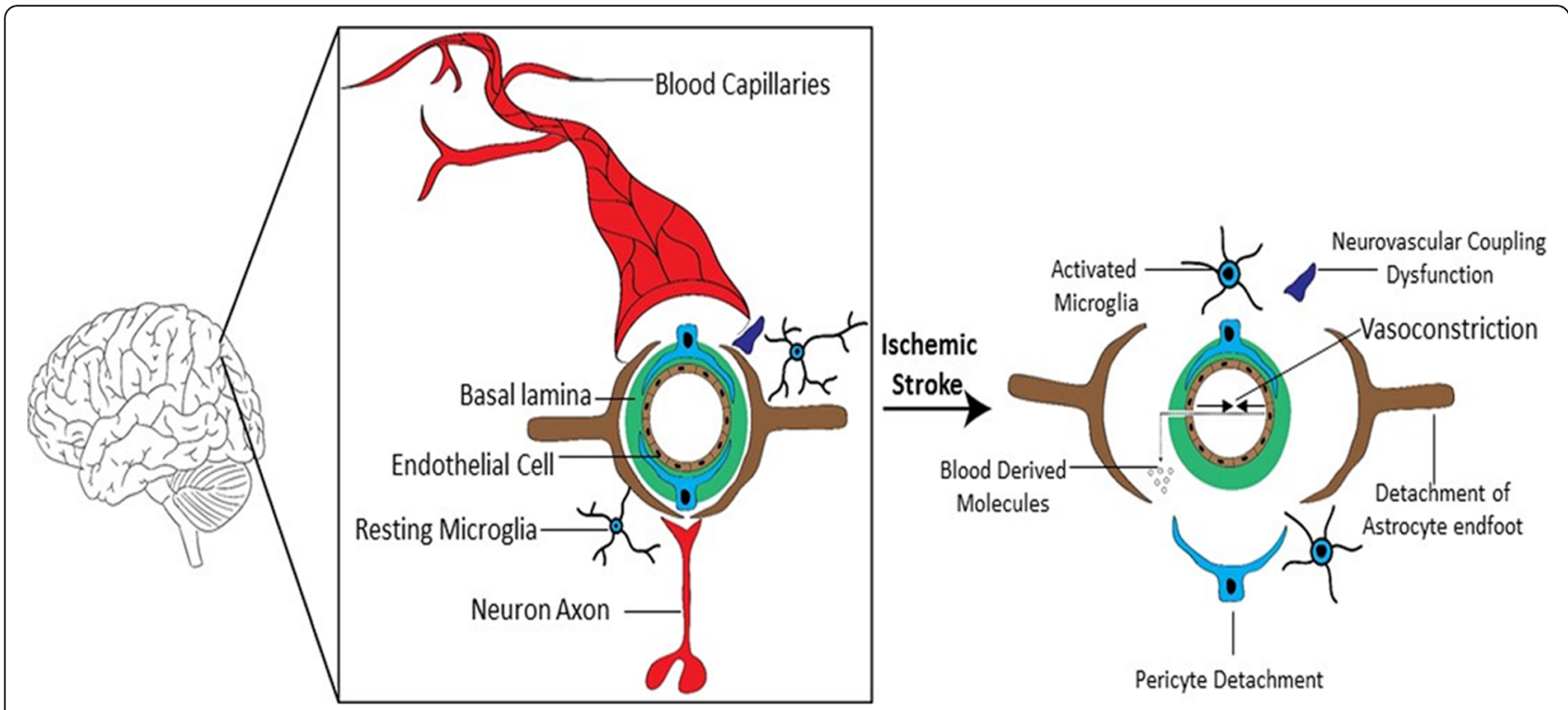

Fig. 1 Schematic representation of the detrimental events following ischemic stroke. Stroke potentiates a cascade of ischemic events that leads to impairment of NVU resulting in BBB damage. Neurovascular unit is made of highly specialized and polarized endothelial cells interconnected by tight junction proteins that seal the brain capillaries. Astrocytes, microglia, and pericytes provide structural and functional support to the BBB. Ischemic stroke leads to NVU remodeling due to detachment of astrocytic endfoot, pericyte detachment, vasconstriction, dysfunction of neurovascular coupling, activation of microglia, and blood vessel rupture

hyperpermeability could help enhance BBB repair. Apart from dexamethasone clinical trial that failed, administration of bortezomib (proteasome inhibitor) along with dexamethasone reduced BBB permeability [66]. Novel therapeutic approaches to enhance BBB repair after stroke have been extensively reviewed elsewhere [67].

\section{Leukocytes}

Similar to other inflammatory cells, leukocytes release proinflammatory factors in the ischemic region of the brain. Leukocytosis has been shown to be a marker of inflammatory response after stroke. Neutrophils are the first bloodborne immune cells to invade the ischemic tissue followed by monocytes [65]. After stroke, neutrophils undergo conformational changes due to extensive adhesion molecules and migrate through the endothelial vessel wall. Later, neutrophils are attracted towards the ischemic area by chemokines via concentration gradients, and neutrophils cause secondary injury by releasing proinflammatory factors, ROS, proteases, and MMPs [68]. These toxic factors impair endothelial cell membrane and basal lamina leading to BBB permeability and post-ischemia edema. Post-invasion (4-6 h) of neutrophils, monocytes adhere to the vessel walls and move towards ischemic regions with its maximum activity at 3-7 days after the insult [69]. Neutrophils play a major pathological role in acute ischemic injury and may also cause atherosclerosis and thrombus formation [70, 71]. Five hours following reperfusion, neutrophils enter the damaged area $[72,73]$. In a permanent MCAO model, $12 \mathrm{~h}$ after the insult, peak neutrophils are reported [74]. Leukocytes potentiate ischemic injury in many ways. First, leukocytes adhere to the endothelium, which blocks the flow of erythrocytes via microvasculature, leading to cerebral no-reflow phenomenon. Second, at the surface of endothelium, activated leukocytes produce proteases, MMPs, and ROS that can significantly damage blood vessels and brain tissues. Further, biologically active substances like eicosanoids, leukotrienes, prostaglandins, and platelet-activating factor are produced when leukocytes are activated by phospholipases, leading to vasoconstriction and platelet aggregation. Finally, leukocytes (infiltrated) further exaggerate neuronal injury by activating proinflammatory factors in and around the penumbra and the infarct core [16]. Furlan et al. demonstrated that leukocytosis is significantly associated with a high degree of disability, impairment, greater risk of total anterior circulation stroke, and higher mortality [75]. Moreover, hypoxia-related genes are upregulated in leukocytes isolated from stroke patients [76]. To conclude, all these inflammatory cells play a significant role in both initiating and aggravating pathological response in stroke as well as in maintaining cellular brain homeostasis (Table 1).

Schematic representation of the role of inflammatory cells in post-ischemic inflammation is shown in Fig. 2. However, time-dependent pathomechanisms play a significant role in determining the severity of stroke outcome.

\section{Time-dependent entry of immune cells during ischemic stroke}

Various animal models [77-80] and clinical studies [81, 82] have demonstrated that following ischemia, apart 
Table 1 Beneficial and detrimental role of inflammatory cells in ischemic stroke

\begin{tabular}{|c|c|c|}
\hline Cell type & Detrimental effects & Beneficial effects \\
\hline $\begin{array}{l}\text { Microglia/ } \\
\text { macrophages }\end{array}$ & $\begin{array}{l}\text { Production of proinflammatory cytokines, including TNF and IL-1, } \\
\text { reactive oxygen and nitrogen species, and proteases, such as } \\
\text { MMPs. Brain microglia/macrophage phagocytose viable and } \\
\text { functional neurons causing brain atrophy. }\end{array}$ & $\begin{array}{l}\text { Resolution of inflammation (IL-10 and TGF- } \beta \text { release, production } \\
\text { of arginase, and phagocytic activity). Late reparative processes by } \\
\text { producing growth factors (IGF-1, brain-derived neurotrophic } \\
\text { factor, and glial cell line-derived neurotrophic factor), production } \\
\text { of neurotrophic factors, facilitation of neurogenesis and plasticity, } \\
\text { and scavenge and removal necrotic debris }\end{array}$ \\
\hline Astrocytes & $\begin{array}{l}\text { Production of inflammatory mediators (e.g., TNF-a, IL-1, and } \\
\text { MMPs). Edema formation, inhibition of axon regeneration and } \\
\text { BBB disruption, glial scar formation, and glutamate release }\end{array}$ & $\begin{array}{l}\text { Extracellular glutamate uptake, synthesis, and release of } \\
\text { neurotrophic factors. Glial scar formation, BBB rebuilding, and } \\
\text { neurovascular remodeling. }\end{array}$ \\
\hline Neutrophils & $\begin{array}{l}\text { Microvessel obstruction, ROS production, and release of MMPs } \\
\text { that contribute to BBB damage and exacerbate inflammation, } \\
\text { stimulation of lipid peroxidation, release of proteolytic enzymes, } \\
\text { damage of endothelial cell membrane, increase of BBB } \\
\text { permeability, post-ischemic edema, no-reflow phenomenon }\end{array}$ & N2 phenotype: promote resolution of inflammation \\
\hline Dendritic cells & $\begin{array}{l}\text { Up-regulation of MHC-II and co-stimulatory molecules } \\
\text { that prompt the activation of lymphocytes }\end{array}$ & \\
\hline T Lymphocytes & $\begin{array}{l}\text { Facilitate adhesion of platelets and leukocytes to the } \\
\text { vascular endothelium causing thromboinflammation } \\
\text { and promoting proinflammatory pathways }\end{array}$ & $\begin{array}{l}\text { Interaction of T cells with platelets may also } \\
\text { have hemostatic effects preventing hemorrhagic transformation } \\
\text { after severe ischemic stroke }\end{array}$ \\
\hline
\end{tabular}

from activation of microglial cells in the ischemic brain, infiltration of circulating cells, such as granulocytes, neutrophils, monocytes/macrophages, and $\mathrm{T}$ cells, occurs aggravating cell death. During an acute phase, lasting minutes to hours, the injured tissue releases reactive oxygen species (ROS) and proinflammatory factors, such as chemokines and cytokines, which induce the expression of adhesion molecules on leukocytes and on cerebral endothelial cells that in turn promote adherence and transendothelial transfer of leukocytes [83].

Following the acute phase, in the sub-acute phase, the infiltrated leukocytes further release cytokines, chemokines, and more importantly excess ROS that promotes production of matrix metalloproteinases (MMPs) especially MMP-9. Jalal et al. and various groups have proven that MMP activation intensifies an inflammatory response, leading to $\mathrm{BBB}$ disruption, brain edema, neuronal death, and hemorrhagic transformation due to excessive activation of proteases and resident immune cells, and further intensifies leukocyte infiltration $[84,85]$. Because of the complex nature of the interaction of the proinflammatory factors with the tissues, they act in multiple roles. For example, MMP-9 not only acts as a proinflammatory factor in early ischemic brain damage, but also plays a major role in brain regeneration and neurovascular remodeling during repair $[53,86]$. Hence, it is critical to understand the time course of inflammatory events and cells involved that lead to ischemic brain injury.

\section{Resident microglia and blood-derived macrophages}

Various reports have shown that microglia, the resident macrophages of the brain, are activated within minutes after ischemic onset leading to production of various proinflammatory factors, such as interleukin-1 $\beta$ (IL-1 $\beta$ ) and tumor necrosis factor-alpha (TNF- $\alpha$ ), aggravating brain damage [14, 87]. Apart from being a proinflammatory stimulator, microglia cells also promote excitotoxic injury and ischemia in the brain [88]. Following ischemia, microglia proliferation peaks at $48-72 \mathrm{~h}$ and lasts for a few weeks after the initial injury [89], but contradictory to this, blood-derived leukocytes are recruited hours to a few days after initial injury [70, 90].

Since blood-derived monocytes/macrophages and reactive microglia are almost morphologically and functionally similar, it has been challenging to differentiate these cells due to lack of cell-specific markers [79, 80, 91]. Blood-derived macrophages patrol the brain to capture potential pathogens, and just like microglia, bloodderived macrophages are able to acquire a ramified morphology. Furthermore, microglia have the ability to develop a phagocytic phenotype very similar to macrophages. Hence, it is very challenging to distinguish between these two cell types, but an excellent work by Tanaka et al. using chimera mice with enhanced green fluorescent protein (GFP) bone marrow provided a useful tool to differentiate the role of resident as well as blood-derived macrophages in ischemic brain injury [80]. Many literature reports have shown that 3-4 h after stroke, blood-derived macrophages are recruited into the ischemic brain tissue [92, 93]. Schilling et al. using a transient middle cerebral artery occlusion (MCAO) chimera mouse model demonstrated that resident microglia activation predates and dominates bloodderived macrophages [91, 92]. These reports proved that following brain damage, neutrophils are the first bloodderived leukocytes observed at day 1 while GFP positive 


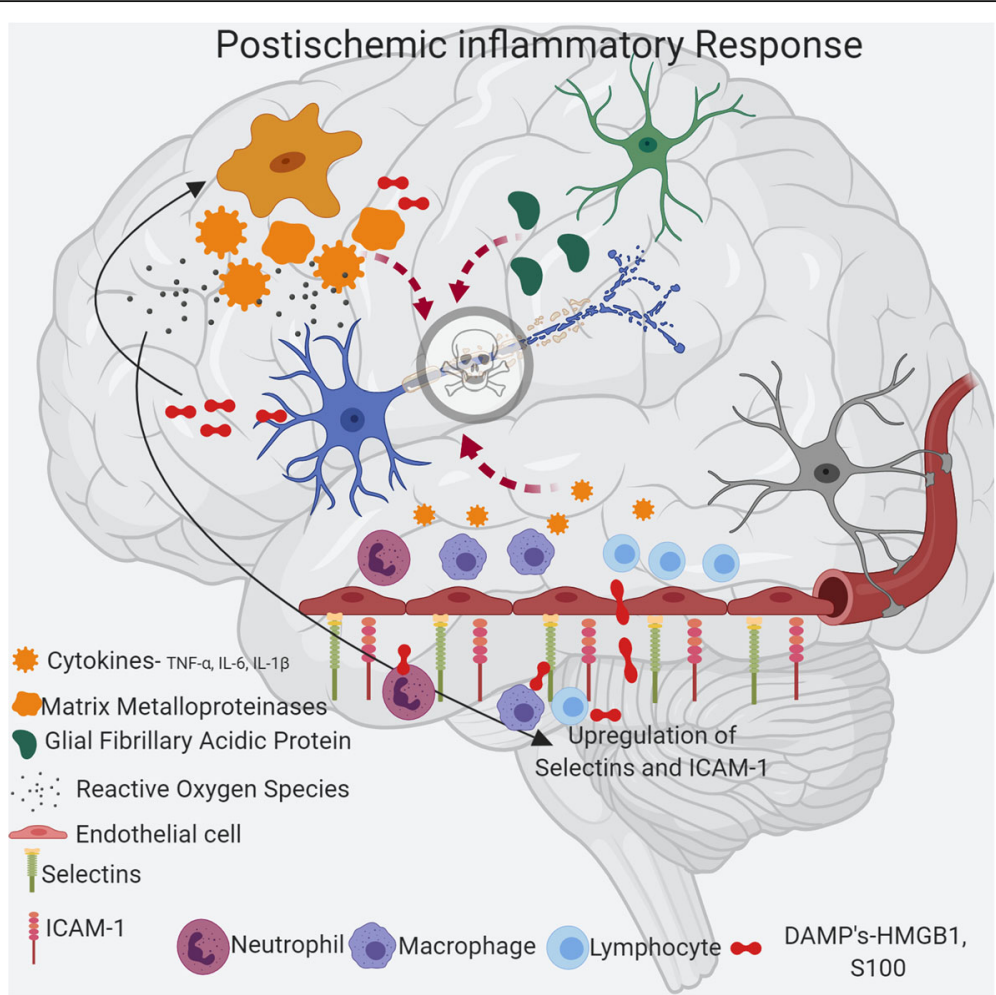

Fig. 2 Schematic representation of post-ischemic inflammatory response in stroke. Initial ischemic event leads to oxidative stress and excitotoxicity which causes activation of microglia and astrocyte resulting in secretion of cytokines, MMP, and GFAP. These proinflammatory factors leads to upregulation of cell adhesion molecules such as ICAM-1 and selectins on endothelial cells causing inflow of blood derived inflammatory cells such as neutrophils, macrophages, and lymphocytes to the ischemic area. In addition, danger-associated molecular patterns (DAMPs) are released by dying neurons that in turn activates microglia and peripheral immune cells (neutrophil, macrophage, and lymphocyte) resulting in production of proinflammatory factors causing further activation of microglia and astrocyte. These pathological events lead to neuronal death and further increase damage to the ischemic brain

blood-derived macrophages were rarely seen at day 2 but their number peaked at day 7 and declined thenceforth. Contrary to blood-derived macrophages, even at day 1, GFP-negative microglial (resident) cells are activated rapidly, and interestingly, even at days 4 and 7 , most macrophages are resident microglia (GFP-negative) in mouse models of transient and permanent MCAO $[80,94]$. Recently, in an effort to understand the gene expression patterns of resident microglia and bloodderived macrophages after stroke, Kronenberg et al. used bone marrow chimerism and dual reporter transgenic fate mapping to distinguish the responses in MCAO mouse model. Biased gene expression analysis in 7 days post-stroke tissue provided 970 transcripts predominantly overexpressed in microglia and 472 transcripts expressed in blood-derived macrophages. These expression levels were further compared with transcriptomes of astrocytes, oligodendrocytes, and neuronal populations that resulted in specific genes expression in microglia and blood-derived macrophages. Genes upregulated in blood-derived macrophages are functionally involved in migration, proliferation, and calcium signaling which was further confirmed by whole-cell patch clamp technique. In addition, blood-derived macrophages were more altered towards neuroprotective M2 phenotype. Further, using Selplg-/- (gene encoded for P-selectin glycoprotein ligand-1, an important factor for leukocyte recruitment in inflamed site) chimera mice, the group found that the lack of Selplg gene lowered engraftment of blood-borne cells in the ischemic brain and enhanced lesions at 7 days with poor sensorimotor performance [95]. Together, these data represent that during the first few days following cerebral ischemic injury, the majority of macrophage-like cells represent activated microglia.

\section{Neutrophils}

Apart from microglia and blood-derived macrophages, neutrophils are one of the most important leukocytes that infiltrate the ischemic brain from $30 \mathrm{~min}$ to a few hours, peaking between days 1-3 following which they steadily decline over time [69]. Weston et al. reported that infiltrating neutrophils remain more than 32 days in endothelin-1-induced ischemic brain regions but their presence is masked after 3 days by the concentration of 
activated microglia/macrophages in the inflammatory region. Further, neutrophil infiltration elevates at day 1, spikes at day 3, and begins to decline, but is present through day 7 and 15 after cerebral ischemia. Neutrophils express various endothelial adhesion molecules within 15 min post-ischemia [96]. Six to $8 \mathrm{~h}$ after stroke, neutrophils have already surrounded cerebral vessels and initiates infiltration [97, 98]. Alternatively, flow cytometry analysis by Gelderblom et al. using a transient MCAO model demonstrated that other inflammatory cells such as macrophages, lymphocytes, and dendritic cells precede neutrophil influx in the ischemic hemisphere [99]. Consistent with other reports $[69,100]$, Gelderblom et al. demonstrated that neutrophils are the predominant cells present in the ischemic hemisphere at 3 days after MCAO [99]. Neutrophil increase has been positively correlated with infarct volume and functional deficits [69]. Neutrophil rise might be due to enhanced release from the bone marrow and spleen along with less neutrophil apoptosis [101]. In contrast to neutrophils, lymphocytes number decrease in ischemic stroke and hence neutrophillymphocyte ratio is increased. This ratio is closely associated with infarct size and mortality [102].

\section{T lymphocytes}

Unlike neutrophils, $\mathrm{T}$ lymphocytes are recruited in the later stages of ischemic brain injury [103]. Jander et al. analyzed leukocyte infiltration in photochemically induced focal ischemia of rat parietal cortex by immunocytochemistry and reported that by day 3 , numerous $\mathrm{T}$ cells infiltrated the border zone around the lesion by sparing the center and their number elevated between days 3 and 7 [104]. Similar to this study, Stevens et al. using a transient MCAO mouse model demonstrated that $\mathrm{T}$ cell $\left(\mathrm{CD}^{+}\right)$infiltration increases at days $3-4$ postischemia while activated microglia $\left(\mathrm{CD} 11 \mathrm{~b}^{+}\right) /$macrophages and neutrophils $\left(\mathrm{Ly}_{6 \mathrm{G}}{ }^{+}\right)$increased at earlier time points post-ischemia. Nevertheless, few reports demonstrated that $\mathrm{T}$ cells accumulate within the first $24 \mathrm{~h}$ in the ischemic brain following cerebral ischemia (MCAO), which might play a major role in influencing tissue inflammation and injury prior to the appearance of these cells in the extravascular space $[105,106]$. Research efforts are increasing to reveal the role of different $\mathrm{T}$ cell subtype in ischemic stroke. Various studies have demonstrated that after stroke, $\mathrm{CD}^{+}$, non-Treg $\mathrm{T}$ cells, $\mathrm{CD} 8^{+} \mathrm{T}$ cells, Tregs, and $\gamma \delta$ T cells infiltrate brain parenchyma [107]. Numerous research groups are focusing on modulating the activity of Treg cells due to their neuroprotective activity. Immunodepletion of Treg using CD-25 specific antibody aggravated tissue loss and impaired neurological function at day 7 after MCAO-induced ischemia in mice [108]. However, different approaches to suppress Treg led to controversial results [109, 110]. Pre-clinical and clinical studies suggest that enhancing the function or number of Treg could be neuroprotective against ischemic injury [107]. However, Treg cell therapy has its own challenges such as isolation and purification of Treg, period for ex vivo Treg expansion, and anergic property of Treg.

Post-stroke pathological mechanisms aggravate cell injury due to primary cellular events, which initiate a pathological viscous cycle of inflammatory mediators that further exacerbates neuronal death. The mediators involved, their beneficial and detrimental role, and recent therapeutic strategies to combat these pathomechanisms are discussed in detail below.

\section{Key pathological events and pathways fueling neuroinflammation \\ Oxidative stress}

Oxidative stress, a disturbance in the balance between the production of reactive oxygen species (free radicals) and antioxidant defenses, is induced in cerebral ischemia especially through inflammation and reperfusion, which increases the production of ROS [111]. Xanthine oxidase and NADPH oxidase are the two key oxidative enzymes that play a major role in the production of superoxide anion, a key radical after stroke. Van Hemelrijck et al. using a rat model demonstrated that hydroxyl radicals $(\mathrm{OH} \bullet)$ are elevated $2 \mathrm{~h}$ after stroke onset [112]. Nitric oxide (NO), a key radical, is produced by enzymatic conversion of $\mathrm{L}$-arginine by three types of nitric oxide synthases (NOS) namely neuronal (nNOS), endothelial (eNOS), and inducible NOS (iNOS), which are elevated after brain ischemia. Although endothelial NOS is upregulated directly after brain ischemia, neuronal NOS and inducible NOS are upregulated only after a day and even later, respectively [112]. Nitric oxide has both beneficial and detrimental roles in cerebral ischemia. Although NO plays a major role in restoring blood supply to the ischemic area, reducing brain damage, it also reacts either with superoxide anion to form radicals or with free electrons to form peroxynitrite, contributing to lipid peroxidation, cellular toxicity, and eventually cell death [113]. In addition to the action of NO on free radicals, it also enhances the expression of adhesion molecules and inflammatory mediators, inhibits enzymes necessary for DNA replication, and promotes iron loss from cells [114]. The pathological effects of NO on brain tissue damage largely depend on the sensitivity of the cell to $\mathrm{NO}$, concentration of $\mathrm{NO}$, and whether the inflammatory phase is acute or chronic [115]. Knockout animal studies showed that mice lacking nNOS had reduced infarct volume, which demonstrates that $\mathrm{NO}$ produced by nNOS leads to tissue damage. Alternatively, injury after ischemic stroke increased in mice lacking eNOS showing the protective function of eNOS by dilating the blood vessels resulting in normal blood flow to 
the penumbra [116]. Furthermore, disruption of iNOS did not affect infarct volume after day 1 , but after $72 \mathrm{~h}$, iNOS disruption increased infarct size [117]. Various antioxidants such as vitamins, lipoic acid (LA), and $N$-acetylcysteine have been tested for efficacy in stroke [118]. Vitamin E and its analog MDL 74,722 have been reported to reduce lesion volume and behavioral impairments in rodent ischemic stroke models [119-121]. Alternatively, a follow-up study in human subjects demonstrated that vitamin $\mathrm{E}$ and $\mathrm{C}$ did not reduce the risk of ischemic stroke and did not enhance functional recovery in stroke patients, respectively [122-124]. In addition, other antioxidants such as EPC-K1, a phosphate diester of vitamin $C$, reduced lesion size, lipid peroxidation, and renal reperfusion injury in rat model $[125,126]$. Apart from dietary antioxidants as supplements which had little or no effect in clinical trials, NXY-059, tirilazad, edaravone, and citicoline are being studied in clinical patients for its efficacy in treatment of ischemic stroke [118]. However, NXY-059 and tirilazad failed to provide clinical improvement in larger clinical trials [127, 128]. In 2001, edaravone was approved in japan to treat acute phase cerebral infarction. In 2015, edaravone was approved by Japan and in 2017, by the US Food and Drug Administration, for treatment of amyotropic lateral sclerosis [129]. However, a clinical study demonstrated that early-stage edaravone treatment delayed progression of infarction and edema and reduced acute-phase mortality, but edaravone alone did not cause any significant functional recovery [130]. Citicoline is now being reported as a potential therapeutic candidate for ischemic stroke. Citicoline, which is also called as cytidine 5'-diphosphocholine (CDP-Choline), is a combination of two molecules, cytidine, and choline. These molecules are efficient in crossing BBB and then they combine to form CDP-Choline in brain cells [68]. During ischemia, phosphatidylcholine is broken down into free radicals and fatty acids that worsen ischemic injury [131]. The hypothesized mechanism is that citicoline undergoes hydrolysis followed by dephosphorylation to form cytidine and choline and these two molecules act as substrates to re-form citicoline in the brain. This process minimize phospholipid breakdown and enhance phospholipid resynthesis for membrane repair [132]. In addition, citicoline also scavenges free radicals providing antioxidant and anti-inflammatory roles after ischemic damage [133]. Clark and his colleagues reported that 24 $\mathrm{h}$ post-MCAO, administration of citicoline for 28 days enhanced motor and functional recovery [131]. Due to promising biological properties, citicoline has also been administered (500 and $2000 \mathrm{mg}$, i.v.) in a randomized controlled trial [134]. However, other randomized, placebo, controlled clinical studies have reported that citicoline has limited benefits [135-137]. The controversial results might be due to methodological limitations such as odda ratios rather than risk ratio and the use of cumulative meta-analysis rather than trial sequential analysis. The results of International Citicoline Trial on Acute Stroke (ICTUS) was published by Davalos et al. where 2298 patients with moderate to severe stroke (within $24 \mathrm{~h}$ ) of the anterior territory were randomly assigned to double-blinded treatment with $2000 \mathrm{mg}$ citicoline daily or placebo for 6 weeks. Assessment for baseline characteristics and a known risk factor for stroke showed that citicoline-treated patients had well-balanced baseline characteristics risk factors for stroke. However, no significant difference was noted in primary outcome of recovery assessed by mRS score. Evaluating other pre-specified subgroups showed beneficial effects of citicoline in patients older than 70 years and in patients with less-to-moderate stroke. Thus, up-to-date meta-analysis of all clinical trials of citicoline resulted in overall beneficial effect with an odds ratio of 1.14 of achieving good clinical outcome compared to controls [138]. Despite the pros and cons, citicoline is the only promising drug in confirmative clinical trials and no other neuroprotective compound had any positive effect on subgroup analysis [138].

\section{Cytokines}

Cytokines are immunomodulating agents and they play a major role in cell activation, proliferation, and differentiation [139]. Cytokines are generally small pleiotropic polypeptides $(8-26 \mathrm{kDa})$ barely detectable in the brain with their receptors constitutively expressed at very low levels. Cytokines play a major role in upregulating the expression of cell adhesion molecules (CAM) [140, 141]. Especially, intracellular adhesion molecule 1 (ICAM 1) upregulation in the ischemic core leads to BBB disruption by aiding recruitment of leukocytes, which in turn release cytokines. BBB disruption causes migration of various inflammatory cells such as macrophages, natural killer cells, T lymphocytes, and polymorphonuclear leukocytes to the ischemic site. Various studies have demonstrated that infiltrating leukocytes and microglia elevate cytokines and some studies have reported that resident neurons and glia also produce cytokines following brain ischemia [106, 142, 143]. However, upon brain injury, the expression of pro- and anti-inflammatory cytokines is upregulated, but their spatial and temporal upregulation largely depends on the type of ischemic model used [72, 144, 145]. The three major proinflammatory cytokines are interleukin $1 \beta$ (IL-1 $\beta$ ), tumor necrosis factor-alpha (TNF- $\alpha$ ), and interleukin-6 (IL-6) that provoke and aggravate an inflammatory response after stroke [146, 147]. Post-mortem studies demonstrate that TNF- $\alpha$ positive cells are observed in brains of severe ischemic stroke patients from 3 days post-stroke, staying positive until 15 months [148]. Tumor necrosis 
factor- $\alpha$ serum levels are increased within $6 \mathrm{~h}$ poststroke and their levels are maintained for 10 days [149]. Similarly, IL-1 $\beta$ levels are elevated in the CSF with peak levels at days 2 and 3 post-stroke [150, 151]. However, some studies have shown no increase in IL-1 $\beta$ levels in serum and plasma, which might be due to IL-1 $\beta$ localization at the inflammatory site [152]. Interleukin$1 \beta$ mediates ischemic, traumatic, and excitotoxic brain injury through its action on neurons, glia, and vasculature. Similar to TNF- $\alpha$ and IL-1 $\beta$, Il-6 levels are elevated in CSF of severe stroke patients. Few studies report that CSF IL-6 levels increase within $24 \mathrm{~h}$ and peak at days 2 and 4 [153], while some studies report peaking at days 3 and $7[154,155]$. However, their levels appear to be dependent on stroke type and severity. Interleukin $1 \beta$, an important mediator of neuroinflammation, upregulates the expression of IL-6. Hence, IL-1 $\beta$ receptor antagonist, anakinra administration, demonstrated good clinical improvement and decreased peripheral neutrophil count and IL-6 levels [156]. Alternatively, transforming growth factor- $\beta$ (TGF- $\beta$ ) and IL-10 are anti-inflammatory cytokines that inhibit the expression of proinflammatory cytokines thereby reducing inflammation after ischemic stroke $[157,158]$. These pro- and anti-inflammatory agents act as predictors and help in prognosis in ischemic injury. However, other cytokines also contribute to brain damage and repair, but the balance between the beneficial and detrimental effects of cytokines largely depends on the biochemical and physiological status of the brain [158].

\section{Chemokines}

Chemokines are small signaling proteins $(8-10 \mathrm{kDa})$ belonging to the family of cytokines. They have the ability to induce directed chemotaxis in nearby responsive cells, especially leukocytes $[159,160]$. There are 40 different chemokines known so far; they all share a similar structural pattern with 4 cysteine residues and, based on that, they are classified into four subfamilies that play a major role in stroke with $\mathrm{C}-\mathrm{X}-\mathrm{C}$ attracting neutrophils and C$\mathrm{C}$ attracting monocytes/macrophages [161]. The other two classes being $\mathrm{C}$ and $\mathrm{CX} 3 \mathrm{C}$ where $\mathrm{Cs}$ denote two $\mathrm{N}$ terminal cysteine residues and depending on whether amino acid is between them or adjacent to them, they are classified as CXC and CC, respectively. Similar to cytokines, chemokines have both unique and overlapping receptors, which belong to the superfamily of G-proteincoupled receptors [162]. Identical to cytokines, chemokines and their receptors are usually expressed in low concentrations [163, 164], but after cerebral ischemia, TNF- $\alpha$ and IL- $1 \beta$ enhance the production and release of specific chemokines such as cytokine-induced neutrophil chemoattractant (CINC), monocyte chemoattractant 1 (MCP-1), microglial response factor-1 (MRF-1), and fractalkine and macrophage inflammatory protein 1
(MIP-1) which are upregulated in the first $3 \mathrm{~h}$ and remain elevated for at least $6 \mathrm{~h}$ [163]. Chemokines and their receptors play a major role in modulating various pathological and physiological processes, in which their role in post-ischemic inflammation is an important contributor to ischemic brain injury [165]. Brait et al. used PCR arrays to screen temporal expression profile of several chemokine-related genes using focal cerebral ischemia (occlusion for $30 \mathrm{~min}$ ) in mice. Gene analysis at 4, 24 , and $72 \mathrm{~h}$ reperfusion showed that several chemokines belonging to CXC family were upregulated (>10-fold), mediated leukocyte infiltration and played a major role in stroke pathogenesis [166]. Since chemokines have been implicated in the worsening of stroke pathogenesis, their ligands and receptors act as potential therapeutic targets. One such chemokine, chemokine ligand 2 (CCL2) and its receptor CCR2 signaling, mediates pathological post-ischemic inflammatory response by not only inducing leukocyte recruitment but also disrupts BBB and leukocyte adhesion to brain endothelial cells in an MCAO (45 min occlusion) mice model $[167,168]$. CCL2 levels increase in ischemic penumbra from $6 \mathrm{~h}$ of reperfusion with peak levels at 24 and $48 \mathrm{~h}[169,170]$. Levels of CCL2/CCR2 are positively correlated with infarct size and enlargement of the ischemic lesion. Moreover, CCL2 expression is upregulated in the CSF and serum in ischemic patients [171]. Thus, genetic deletion or manipulation of CCL2/CCR2 expression may be a therapeutic target for ischemic stroke. CCL2 gene disruption diminished infarct volume in focal cerebral ischemic mice model (30 min occlusion), and CCR2 deletion not only reduced infarct size and brain edema but also enhanced motor functions in focal transient cerebral ischemia mice model with 30 min occlusion [169, 172]. Alternatively, overexpression of CCL2 exacerbates ischemic injury in mice [170]. In a recent study using CCR2 knockout mice, after MCAO and reperfusion, the infarct size was less in CCR2 KO mice with lower mortality when compared to WT control when measured 3 days after stroke. Nonetheless, CCR2 KO mice had high mortality and neurological deficit from 5 to 28 days after stroke. Hence, CCR-2-dependent monocyte/macrophages not only aggravate brain injury but also alleviate functional recovery after ischemic stroke. Few reports demonstrated that CCR-2-dependent monocyte infiltration to the stroke-injured hemisphere peaked at 3 days after stroke, but after day 7, monocyte-derived macrophages (MDM) exhibited both proinflammatory and anti-inflammatory phenotype equally, but after 2 weeks, macrophages with anti-inflammatory phenotype dominated. However, blocking monocyte recruitment using anti-CCR2 antibody at 1 week post-stroke eliminates long-term behavioral recovery with significant decrease in anti-inflammatory gene expression in an MCAO mice 
model with $30 \mathrm{~min}$ occlusion [173]. Apart from the antiinflammatory mechanisms, MDM regulate and control long-term and acute microglia-mediated neuroinflammation [174]. Hence, manipulation of periphery macrophage control of microglia could be a therapeutic option for treatment for microglia-mediated CNS diseases. Apart from proinflammatory properties of CCR2, CCR-2 recruit bone marrow-derived monocytes/macrophages to prevent hemorrhagic infarct transformation and these cells help maintaining neurovascular unit integrity following ischemia in both photothrombotic and tMCAO mice models [175]. Hence, pharmacological manipulation of CCR2 must be deliberately investigated to avoid impairment of normal physiological function of CCR2. Similar to CCL-2, macrophage inflammatory protein $3 \alpha$ (CCL20) has also been suggested to be involved in proinflammatory macrophage recruitment to the ischemic brain followed by IL- $1 \beta$ and TNF- $\alpha$ production [176, 177]. The initial production of chemokines is attributed to activated microglia (MIP- $1 \alpha$, MIP-2, and MRF-1) followed by astrocytes and injured neurons (fractalkine and MCP-1) after cerebral ischemia [72, 144, 178]. Under pathological conditions, such as brain injury, chemokines act as signals released into cerebrospinal fluid (CSF) and extracellular fluid to recruit neutrophils, monocytes, and microglia [179] whereas under normal physiological conditions, chemokines govern the positioning of cells in tissues and recruit leukocytes to the inflammatory site [180]. Leukocyte recruitment is achieved by chemokines working in harmony with adhesion molecules to affect BBB permeability through diapedesis (passage of blood cells through intact walls of capillaries, generally along with inflammation). Kim et al. also proved that mRNA expression of monocyte chemoattractant protein 1 (MCP-1) was nearly undetectable under normal physiological conditions but after ischemia caused either by permanent or temporary MCAO for around $12 \mathrm{~h}$ or 2 days, resulted in a significant increase in MCP-1 mRNA expression, which persisted for up to 5 days. Supporting this hypothesis, Chen et al. proved that overexpression of MCP-1 exacerbated ischemic brain injury (24-48 $\mathrm{h}$ following occlusion) along with enhanced infiltration of inflammatory cells in MCAO (2h occlusion) mice model [181]. Similar to MCP-1, hindering the activation of MIP-3- $\alpha$ resulted in reduced infarct size in a transient $\mathrm{MCAO}$ rat model with $2 \mathrm{~h}$ occlusion [182]. Chemokine overexpression results in chronic neutrophil infiltration, persistent glial activation, and BBB disruption, resulting in terminal wasting syndrome, but on the other hand, chemokine knockout mice show deficiency in leukocyte recruitment [163, 183]. Apart from their chemotactic properties, chemokines directly affect BBB. Co-culture of brain endothelial cells and astrocytes showed that addition of MCP-1 resulted in a significant increase in BBB permeability and it causes alteration in tight junction proteins (TJP) in endothelial cells and the detrimental action of MCP-1 is diminished by the absence of chemokine receptor type 2 [184]. Hence, chemokines may be a potential target for therapeutic interventions.

\section{Excitotoxicity}

Ischemic stroke causes major ATP and phosphocreatinine depletion that results in the release of excitatory amino acids that leads to excitotoxic neuronal damage called excitotoxicity. Barone et al. reported that accumulation of potassium ions and acidosis are preceding events in the ischemic cascade leading to ionic disturbances [185]. Increase in potassium $\left(\mathrm{K}^{+}\right)$levels leads to the release of glutamate, which in turn stimulates $\mathrm{Na}^{+} /$ $\mathrm{Ca}^{2+}$ channels coupled to $N$-methyl- $D$-aspartate receptors (NMDAR). This further elevates $\mathrm{Na}^{+}$and $\mathrm{Cl}^{-}$levels along with passive influx of $\mathrm{H}_{2} \mathrm{O}$ resulting in cyotoxic edema. Extracellular glutamate also activates $\alpha$-amino-3hydroxy-5-methyl-4-isoxazolepropionic acid (AMPA) and metabotropic glutamate receptors, which is a critical step in the inflammatory cascade [186]. Metabotropic and NMDA receptors work through monoionic channels and incidentally enhance intracellular $\mathrm{Ca}^{2+}$ levels. Various detrimental pathways including voltage and receptor gated $\mathrm{Ca}^{2+}$ influx leads to a significant increase in free cytosolic calcium levels thereby creating mitochondrial calcium overload and further compromising ATP production [185]. Moreover, high intracellular $\mathrm{Ca}^{2+}$ levels lead to the activation of proteases, lipases, kinases, phosphatases, endonucleases, and free radicals that promote breakdown of phospholipids, proteins, and nucleic acids $[187,188]$. In normal physiological state, $\mathrm{Mg}^{2+}$ blocks channel pores of NMDA receptor, but when glutamate is released from pre-synaptic sites and when AMPA receptors are activated, $\mathrm{Mg}^{2+}$ is completely removed from NMDARs due to partial depolarization in post-synaptic membrane. This causes influx of $\mathrm{Na}^{+}$and $\mathrm{CA}^{+}$into the cell that plays a major role in ischemic cell death [189, 190]. Calcium overload inside neurons activates a series of downstream death signaling pathways such as calpain activation [191], ROS production [192], and mitochondrial impairment [193]. Hence, NMDAR antagonists have been rigorously studied as a therapeutic candidate for treatment of ischemic stroke. In specific, GluN2Aand GluN2B-containing NMDAR are the two important NMDAR in adult forebrain. During an ischemic event, activation of synaptic and extra synaptic GluN2Bcontaining NMDARs leads to excitotoxicity followed by neuronal apoptosis. Alternatively, activation of GluN2Acontaining NMDARs also results in neuroprotection and neuron survival $[194,195]$. Hence, dual roles of 
NMDARs might depend on subcellular locations and subtypes of the receptors that are activated. GluN2B, PSD95, and nNOS complexes play a major role in the activation of death signaling pathways during ischemic stroke [196]. Post-synaptic density protein-95 (PSD-95), a scaffolding protein, links NMDARs to downstream molecules, such as nitric oxide synthase (NOS). PSD-95 is made up of three PDZ domains in which PDZ1 and PDZ2 bind to threnonine/serine- $\mathrm{x}$-valine- $\mathrm{COOH}(\mathrm{T} / \mathrm{SXV})$ motif at the intracellular c-termini of GluN2 containing NMDAR subunits [197]. Also, PDZ2 of PSD95 binds to $\mathrm{N}$-terminus of nNOS. Both these events lead to $\mathrm{Ca}^{2+}$ influx from overactivation of nNOS, followed by excess production of nitric oxide (NO), an effector of excitotoxicity [198]. Hence, disrupting GluN2B-PSD95-nNOS complex impairs NO production and prevents excitotoxicity based neuronal damage [199]. One such study showed that "TatNR2B9c or NA-1," an interfering peptide that binds to either PSD95 or nNOS, prevents the activation of downstream neurotoxic pathways and neuronal superoxide production in neuronal cells [200]. In vitro studies have also demonstrated that administration of Tat-NR2B9c after ischemic stroke reduced infarct volume and improved behavioral outcomes [201]. Cook and his colleagues mimicked clinically relevant situations in a gyrencephalic non-human primate MCAO model and demonstrated that Tat-NR2B9c reduced infarct size (MRI and histology), maintained the ability of ischemic cells to preserve genetranscription in genome-wide screens, and also prevented behavioral impairment [199]. A double-blinded, randomized, controlled proof-of-concept study conducted across 14 hospitals in the USA showed that NA-1 administration decreased ischemic infarcts. This study was performed on patients who had ruptured or unruptured intracranial aneurysm amenable to endovascular repair because diffusion-weighted MRI showed $90 \%$ of patients undergoing endovascular repair show small, embolic procedurally induced ischemic stroke [202]. In addition to peptides, small molecules targeting GluN2B-PSD95-nNOS complex are being studied. In vitro and in vivo studies demonstrated that ZL006 was reported to selectively obstruct PSD95 and nNOS interaction during ischemia. In addition, ZL006 did not affect the normal physiological role of MNDARs and nNOS [196, 203]. Similarly, IC87201 disrupted pathogenic PSD95-nNOS interaction without impairing normal nNOS activity in neurons [204]. However, biochemical and biophysical studies using fluorescence polarization (FP), ${ }^{1} \mathrm{H}_{-}{ }^{15} \mathrm{~N}$.HSQC NMR and isothermal titration calorimetry have shown that under applied in vitro conditions, both ZL006 and IC87201 do not interfere with PDZ domains of nNOS or PDS-95 and it also does not inhibit nNOS-PDZ/ PSD-95-PDZ interface [205].

Currently, safety and optimal neuroprotection of Neu2000 in ischemic stroke with endovascular recanalization (SONIC) trial is being performed to evaluate the neuroprotective efficacy of Neu2000 before endovascular thrombectomy in ischemic stroke patients [206]. Neu2000, a sulfasalazine derivative, selectively blocks NMDA receptors along with robust free radical scavenging property. Preclinical animal models demonstrated favorable efficacy and therapeutic window profile [207]. Apart from these small molecules, neuroprotective efficacy of peroxynitrite scavenger, disufenton sodium (NXY-059), uric acid, and antioxidants (edaravone) were evaluated using rodent models and clinical trials (discussed in detail in the "Oxidative stress" section). Free radicals also promote $\mathrm{BBB}$ disruption, brain edema and it has been reported that there is a significant decrease in free radical scavenging enzymes (superoxide dismutase) and increase in NO levels during ischemic stroke. In conclusion, decrease or decline in cerebral blood flow drains energy that is required for cellular ionic homeostasis. Ischemia-induced depolarization results in increased glutamate release, which leads to activation of endonucleases [208]. Hence, NMDA and AMPA receptor antagonists can be developed as neuroprotective agents that can inhibit depolarization and prevent ionic perturbations. Glutamate receptor-mediated excitotoxicity is also activated by death molecules like Fas ligand, generated by matrix metalloproteinase, matrilysin [209]. Tissue inhibitor of matrix metalloproteinase 1 (TIMP1) inhibits excitotoxic-mediated neuronal death [210]. Hence, the role of MMPs in aggravating ischemic neuronal death is discussed below.

\section{Matrix metalloproteinases}

Matrix metalloproteinases (MMPs) are a large family of proteolytic enzymes that degrade all components of extracellular matrix [211]. MMPs range from matrilysin (267 amino acids), being the smallest member of the family to large transmembrane proteins such as MMP14 (582 amino acids). All MMPs have a definitive configuration consisting of the catalytic zinc site, the propeptide region, the fibronectin binding site, and the transmembrane site. MMPs are broadly classified into constitutive (MMP-2 and MMP-14) and inducible (MMP-3 and MMP-9) enzymes, where constitutive enzymes act close to the site of activation whereas inducible enzymes are not constrained to act at the activation site [53]. Although, MMPs act as proinflammatory factor, they are also important for normal physiological function such as neuronal regeneration, cell proliferation, angiogenesis, and apoptosis [212]. MMPs play a major role in $\mathrm{BBB}$ disruption during the acute phase of ischemic stroke by degrading basal lamina and weakening the blood vessels. MMP-9, an inducible MMP, is a $92-\mathrm{kDa}$ type IV-collagenase initially 
secreted in latent form and is activated by proteolytic processing in the extracellular space. Studies using ischemic rodent models demonstrated that there is a significant increase in the expression of pro/active MMP-9 within $24 \mathrm{~h}$ following ischemia in rats [213], and they have been detected in both central and peripheral cells with a unique expression profile [214, 215]. MMP-9 along with tissue plasminogen activator (tPA) has been reported to disrupt $\mathrm{BBB}$ resulting in hemorrhagic transformation [216]. Rosenberg et al. using an MCAO rat model with $2 \mathrm{~h}$ occlusion demonstrated that the activity of MMP-9 was maximally elevated at $48 \mathrm{~h}$ [217]. MMP-9 is initially produced by endothelial cells and neutrophils, and after 5 days, they are produced by macrophages. During ischemic stroke, endothelial cells overexpress MMP-9 within and at the periphery of ischemic lesions that results in increased vascular permeability. Type IV-collagen, laminin, and fibronectin are the key components of basal lamina that separates cerebral blood vessels from extracellular matrix. Overexpression of MMP-2 and MMP-9 can digest basal lamina, and this digestion begins as early as $2 \mathrm{~h}$ following ischemia, which corresponds with BBB breakdown $3 \mathrm{~h}$ following ischemia [218]. Moreover, following stroke, alterations in other MMPs such as enhanced levels of pro/active MMP-2 [219], MMP-3 [84], MMP-10 [219], and MMP13 [220] have been reported. MMPs have been associated with increase in circulating cytokines [221] and escalation of thrombolysis [222] along with activation of microglia and astrocytes [84]. Various studies demonstrated that MMP inhibition not only reduces infarct size but also alleviates brain edema and hemorrhage [53, 223]. Moreover, when compared to wild-type mice, MMP-9 knockout animals had smaller infarct. Whereas, a similar effect was not observed in MMP-2 knockout mice which demonstrates that MMP-2 may be involved with neovascularization whereas MMP-9 may be involved in edema [224]. Apart from this, MMP levels in plasma could be developed as potential biomarkers since they can be used to predict the severity of stroke. Firstever ischemic stroke patients enrolled in intensive rehabilitation study demonstrated that MMP levels were stable as healthy volunteers during the study period but baseline MMP-12 and MMP-13 were correlated with stroke severity. Surprisingly, plasma MMP3 was significantly increased in patients with better motor/functional recovery [225]. However, serum level of MMP-9 was independently positively correlated with initial stroke severity, as well as with clinical recovery [226]. Since MMPs play both beneficial and detrimental roles in stroke, MMPs are explored as potential therapeutic targets that are reviewed in detail by Yang et al. [53]. Further, MMP-mediated BBB permeability in ischemic stroke is inhibited by cyclooxygenase 2 inhibitors [227].
Hence, modulating the activity of Cox-2 or prostaglandin E2 prevents MMP-mediated BBB disruption.

\section{Cyclooxygenase-an arachidonic acid metabolite}

Activation of immune cells results in the release of phospholipase A2 (PLA2) that leads to initiation of the arachidonic acid (AA) cascade by hydrolyzing glycerophospholipids. This results in subsequent energy failure and depletion of ion concentrations due to intracellular calcium accumulation [228]. Tabuchi et al. demonstrated that AA metabolites act as signaling molecules that initiate a post-ischemic immune response in MCAO (75 min occlusion) mice model. Further, PLA2 deficient mice had small infarcts when compared to wild-type mice demonstrating their detrimental role in brain ischemia [229]. Cyclooxygenase (COX) further metabolizes AA to prostaglandin $\mathrm{H} 2$, once released from brain phospholipids. Cox is present in three isoforms namely Cox-1, Cox-2, and Cox-3 [230], where Cox-1 is constitutive and Cox-2 is inducible. Twenty-four and $96 \mathrm{~h}$ following brain ischemia by MCA occlusion, Cox-1 $1^{-/-}$mice had larger infarcts when compared to $\mathrm{COX}-1^{+/+}$mice which might be due to severe cerebral blood flow reduction in the vulnerable region at the periphery of the ischemic territory [231]. Thus, vascular function of COX-1 plays an important role in maintaining cerebral blood flow in post-ischemic brain. Alternatively, pharmacological inhibition of Cox-1 using Valeryl Salicylate in a model of global cerebral ischemia with 5 min occlusion increased the number of healthy neurons in the hippocampal CA1 even after 7 days post-ischemia [232]. Under normal conditions, Cox-2 is involved in synaptic plasticity and cerebrovascular regulation [233, 234]. Whereas, under disease conditions, their reaction products have a major role in glutamate excitotoxicity [235]. Cox-2, an essential isoform for prostanoid synthesis, has been reported to be enhanced within the ischemic border zone in rat models of focal cerebral ischemia [236]. Autopsy studies have also demonstrated that Cox-2 immunoreactivity has been observed in vascular cells, infiltrating neutrophils and also in neurons sited at the border of an infarct in stroke patients [237, 238]. Prostanoids, a sub-class of eicosanoids, which is reported to be a key factor in the pathological mechanism of ischemic and excitotoxic brain injury, is derived from Cox-2 [235]. Long-term treatment with Cox-2 inhibitors has been shown to elevate the incidence of myocardial infarction and stroke [239]. Hence, it is mandatory to specifically target downstream effectors of Cox-2. Specifically, Cox-2-mediated neurotoxicity is achieved through prostaglandin E2, a downstream effector molecule that acts through four Gprotein-coupled receptor namely EP1, EP2, EP3, and EP4 [240, 241]. These receptors have distinct signal transduction profiles and mostly opposite cellular 
actions [241]. Various studies support the detrimental role of EP1 subtype of prostaglandin E2 receptor in cerebral ischemia [240, 242]. Moreover, administration of EP1 receptor antagonist ONO-8713 followed by striatal unilateral NMDA injection prevents neurotoxicity and diminishes ischemic and excitotoxic brain injury [242, 243]. EP1 receptors augment neurotoxicity by impairing $\mathrm{Na}^{+}-\mathrm{Ca}^{2+}$ exchange leading to disruption of $\mathrm{Ca}^{2+}$ homeostasis and resultant excitotoxic neuronal death. Moreover, pharmacological inhibition of EP1 receptor with SC51089 (EP1 antagonist) $6 \mathrm{~h}$ after MCA reduced brain injury suggesting their importance for therapeutic development [240].

\section{Transcriptional modifications}

It is well known that following cerebral ischemia, there is upregulation of mitogen-activated protein kinase (MAPK) and nuclear factor kappa beta (NF- $\kappa \beta$ ) gene expression, which both play a key role in activation of inflammatory signals [244]. NF- $k \beta$ family shares a Rel homology, and this heteromeric transcription factor is usually made up of a sequel of Rel subunits such as Rel (cRel), Rel A (p65), Rel B, NF- $k \beta 1$ (p50 and its precursor p105), and NF- $\mathrm{k} \beta$. The most common composition of NF- $\mathrm{k} \beta$ is $\mathrm{p} 50$ and $\mathrm{p} 65$ and is normally found in the cytoplasm bound to its inhibitor protein ІкB. ІкB kinase (IKK) phosphorylates an inhibitor of kappa B (ІкB) that leads to ubiquitination and dissociation of І $\kappa B$ from NF- $\kappa \beta$ and eventual degradation of I $\kappa B$ by the proteosome. This process helps NF- $\kappa \beta$ to translocate to the nucleus and bind to specific sites of DNA and in promoter domains of proinflammatory genes that lead to transcription of TNF, ICAM-1, COX-2, iNOS, and IL-6. There is a strong correlation between oxidative stress-mediated neurotoxicity and elevated NF- $\mathrm{\beta} \beta$ expression. NF- $\kappa \beta$ expression contributes to the increase in cell death after MCAO and its activation results in enhanced expression of downstream target genes that play a vital role in neuronal injury. Moreover, either inhibition of p50 or p50 in knockout mice models protects from brain ischemia [245, 246]. Further, Hermann et al. reported that inhibition of IkK markedly reduced infarct size and in contrast activation of IkK enlarged the infarct size. This work is also supplemented by a selective small molecule IkK inhibitor studies that mimicked their genetic studies [247]. Activation of NF- $\mathrm{k} \beta$ and MAPK pathways also leads to the expression and activation of nucleotide-binding oligomerization domain (NOD)-like receptor (NLR) pyrin domain containing 1 and 3 (NLRP1 and NLRP3) inflammasome protein that contributes to neuronal cell death and brain injury following $1 \mathrm{~h}$ occlusion in a MCAO mice model [248].

\section{Mitogen-activated protein kinase (MAPK)}

Mitogen-activated protein kinase (MAPK) family is composed of three groups namely extracellular signal-regulated kinase $1 / 2$ (ERK 1/2), c-Jun N-terminal kinases (JNK), and p38 [249]. Various stress factors such as cytokines, osmotic stress, and microtubule disorganization stimulate MAPK pathway that leads to activation of three-tiered Raf/MEK/ ERK cascade through G-protein-coupled receptors. Stress activated protein kinases (SAPK), JNK, p38 MAPK, and ERK have been reported to play a detrimental role in brain ischemia [250]. Following brain ischemia, activation of MAPK pathway was noticed to occur $30 \mathrm{~min}$ and 3 days, and moreover, many proinflammatory mRNA transcriptions are mediated by $\mathrm{p} 38$ MAPK that suggests its role in inflammation-mediated ischemic brain injury. Following ischemia (90 min occlusion), p38 MAPK signaling plays a major role in ischemia-induced astrogliosis, while p38 inhibition attenuated hypoxia and scratch injury-induced astrogliosis in a MCAO mice model [251]. Phosphorylated p38 MAPK was detected in astroglia [252], microglia [253], and neurons [254] of ischemic brain tissue that demonstrates its role in the inflammatory response. Increased inflammatory factors can strongly activate P38 MAPK forming an injury cycle [255]. Following 2-h middle cerebral artery occlusion, MAP Kinase/ERK pathway plays a major role in the expression of MMP leading to $\mathrm{BBB}$ breakdown and upregulation of proinflammatory factors [256]. Also, inhibition of the MAPK cascade via suppression of cytokines through anti-inflammatory drugs, which blocks p38 MAPK, arrested the production of TNF- $\alpha$ and IL-1 $\beta$ resulting in neuroprotection [185]. Moreover, treatment with a neuronal membrane lipid precursor (CDPCholine) after ischemic stroke resulted in the decrease of phosphorylation in ERK 1/2, MEK $1 / 2$, and ElK-1 transcription factors [19]. Hence, there is increasing evidence that MAPK is a significant regulator of ischemic damage that leads to the possibility of using MAPK as a therapeutic target. Moreover, dioscin, a natural steroid saponin, decreased MAPK phosphorylation and inhibited HMGB1 translocation to the cytosol that resulted in less proinflammatory response [257]. MEK/ERK inhibitor U0126 also decreased HMGB1 expression in reactive astrocytes [258]. These reports suggest that MAPK and HMGB1 pathway act as an important factor in stroke pathology.

\section{High-mobility group box protein family}

Alarmins or danger-associated molecular patterns (DAMPs) are released by dying or necrotic cells, initiating an inflammatory response in ischemic core. DAMPs released in the blood stream also help recruit peripheral immune cells. Several DAMP-s such as nucleic acids, ATP, S100 proteins, and HMGB1 have been found to contribute to the inflammatory response in stroke [259]. High-mobility group box (HMGB) proteins are ubiquitous and abundant DNA binding proteins, and they can act as a trigger of neuroinflammation.A unique structure of HMGB1 helps them to bind to DNA and intracellular 


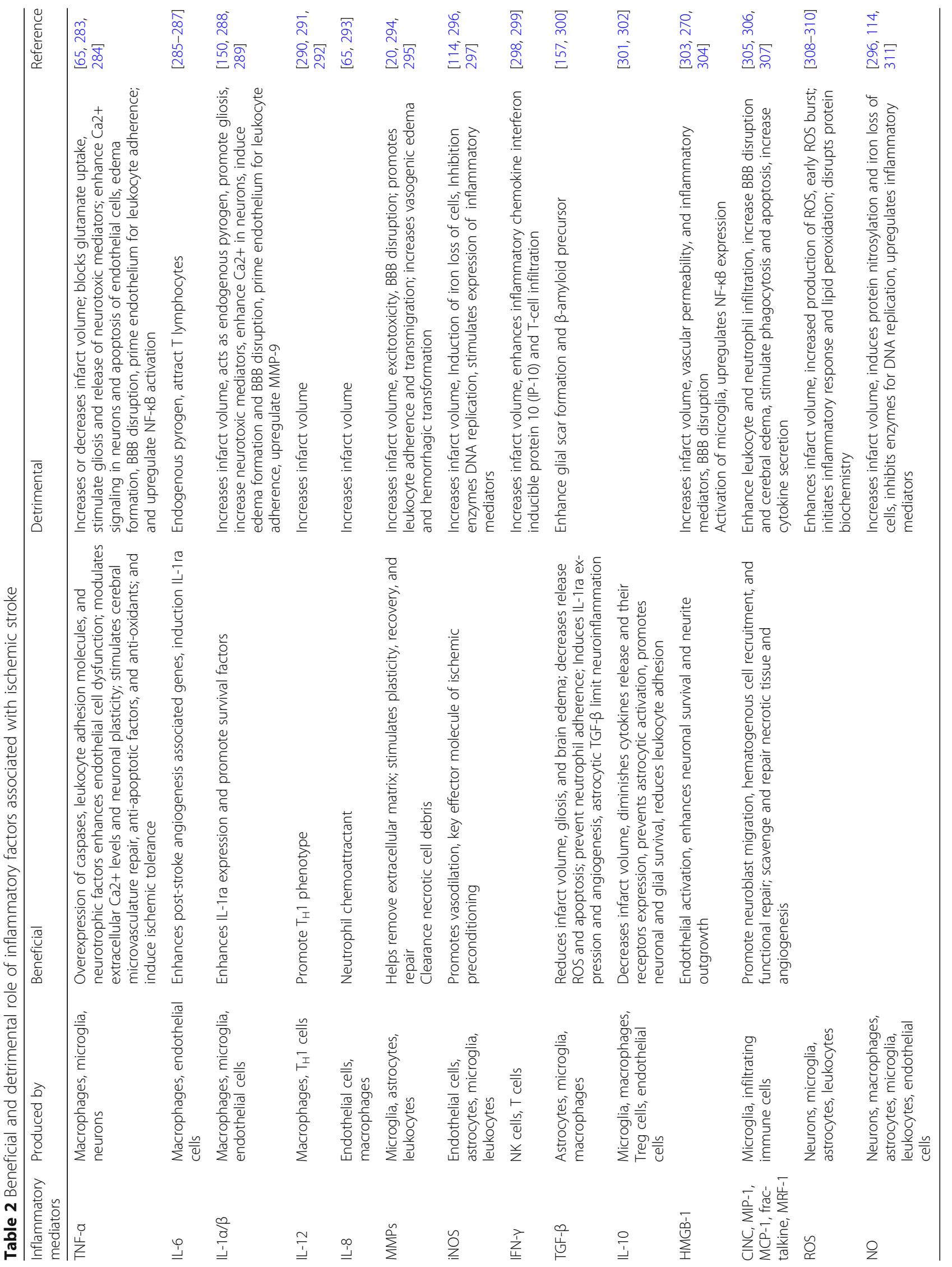


proteins to mediate DNA repair and transcription [260, 261]. HMGB1, also known as amphoterin, was initially described as a non-histone DNA binding protein with high electrophoretic mobility. It plays a major role in nucleosomal structure stabilization and binds to the minor groove of linear DNA without sequence specificity resulting in association of nucleoprotein complexes and recruitment of transcription factors. Although HMGB1 plays a major role in the conservation of nuclear homeostasis, it also acts as an extracellular signaling factor involved in cell proliferation, differentiation, and pathogenesis [262]. Various studies reported that HMGB1 is released in the brain after cytokine stimulation and is associated with inflammation [263, 264]. During cellular stress such as stroke, HMGB1 functions as a proinflammatory cytokine [265, 266]. Following cerebral ischemia in mice, HMGB1 translocates from nucleus to the cytoplasm or within $1 \mathrm{~h}$, it disappears from the cells completely [259]. The expression levels of HMGB1 in microglia, astrocyte, and blood vessels increased dramatically $2 \mathrm{~h}$ after MCAO in mice [267]. Chin et al. recently demonstrated that HMGB1 protects

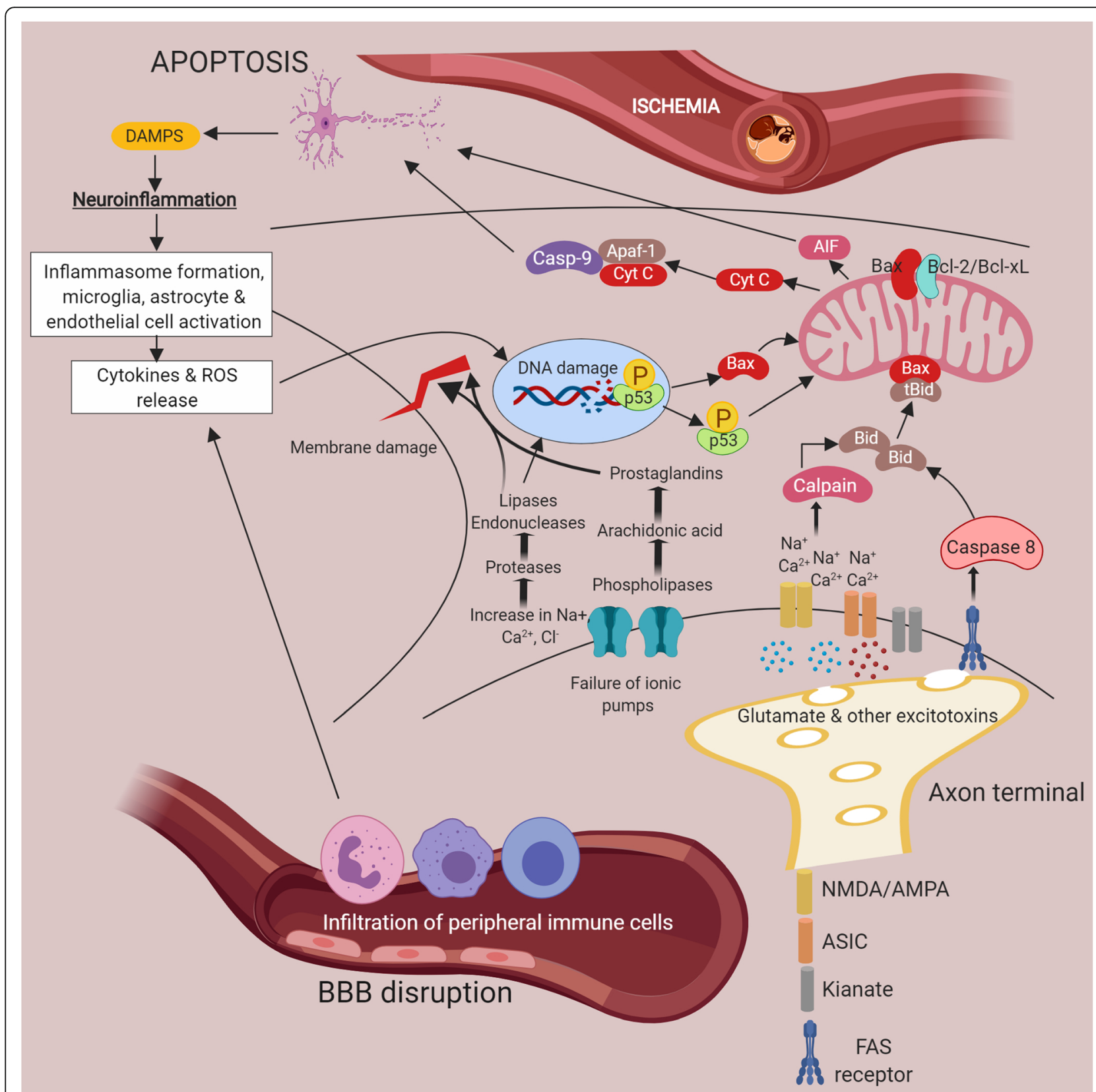

Fig. 3 Apoptotic mechanisms involved in ischemic cell death 
oligodendrocytes and prevents white matter injury during ischemic stress. Mice injected with glycyrrhizin, a specific inhibitor of HMGB1, resulted in expansion of demyelinating lesion along with exacerbated sensorimotor behavioral deficits [268]. HMGB1 is also released by dying oligodendrocyte to act as an autocrine factor under ischemic condition [269]. Clinically, HMGB1 were found to be significantly higher in serum or plasma of patients with ischemic stroke when compared to ageand sex-matched controls [270]. The expression levels of TLR2 on monocytes either stimulated with or without HMGB1 were evaluated in ischemic stroke patients. Real-time PCR and ELISA assays resulted in higher expression of TLR2 in monocytes of stroke patients stimulated with HMGB1. Anti-TLR2 immunomodulation diminished the expression of IL-17, IL-6, and IL-33 [271]. Faraco et al. reported that HMGB1 promotes induction of iNOS, COX-2, IL- $1 \beta$, and TNF- $\alpha$ and also increases excitotoxic as well as ischemic neuronal death in vitro [272]. In addition, there is a strong correlation between MMP-9 and HMGB1 levels in ischemic stroke patients, which was associated with poor outcome [273]. Toll-like receptors 2 and 4 and receptor for advanced glycated end products (RAGE) can bind to extracellular HMGB1 and active transcriptional factor NF-kB [274276]. MyD88, a downstream effector molecule of TLR signaling has been shown to be involved in HMGB1mediated post-ischemic inflammatory response and enhances stroke lesions when compared to MyD88 knockout mice in fMCAO model [277]. Downregulation of HMGB1

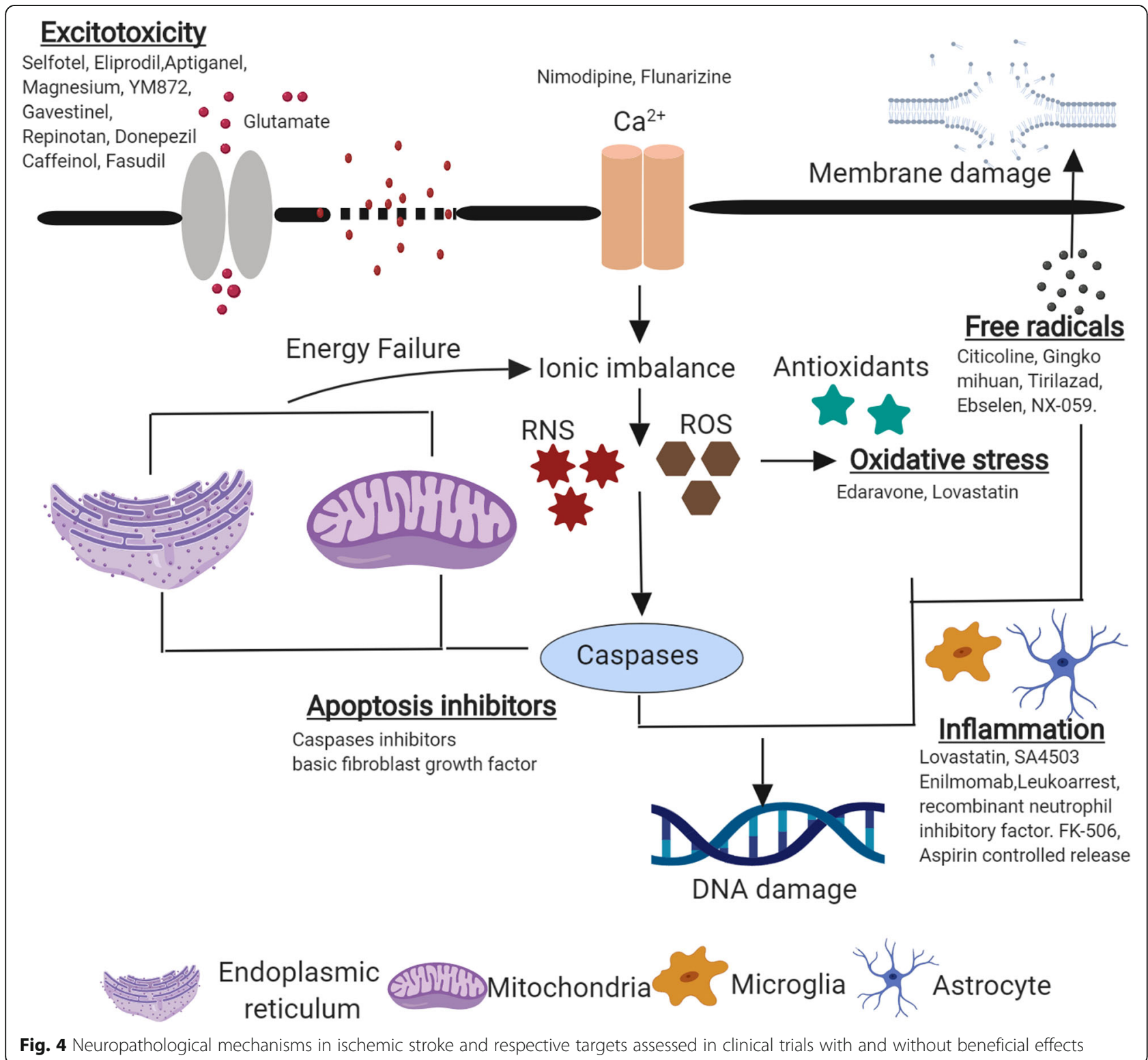


by RNAi (RNA interference) resulted in less microglial activation and reduced infarct volume in rodent MCAO models [278, 279]. Various studies have demonstrated that blocking or modulating HMGB1 by compounds such as statins (atorvastatin, fluvastatin) and by shRNA provided neuroprotective effects against ischemic stroke [280-282].

Hence, similar to other inflammatory mediators, HMGB1 plays an important role in aggravating detrimental events during ischemic stroke. Table 2 summarizes the beneficial and detrimental role of key inflammatory mediators associated with stroke.

To conclude, a cascade of these neuroinflammatory events leads to activation apoptosis and resultant cell death. The molecular events initiated in the brain after ischemic stroke involves a cascade of intracellular mechanisms such as failure of ionic pumps, activation of glutamate receptors that leads to excitotoxicity, increase in calcium influx, and enhanced ROS release that leads to DNA damage and mitochondrial impairment. Intracellular calcium influx is enhanced through activation of $\mathrm{N}$-methyl- $D$-aspartate (NMDA), D,L- $\alpha$-amino-3-hydroxy-5-methyl-isoxazolpropionic acid (AMPA) glutamate receptors, or through acid-sensing ion channels (ASICs). Cerebral ischemia leads to increased ROS production and activation of Fas death receptors which results in the activation of pro-apoptotic caspase-8. Increased ROS results in DNA damage and phosphorylation of p53 that activates nuclear cell death pathways. Caspase-8 or calpains activation further leads to cleavage of Bid to truncated Bid (tBid). Truncated Bid fuses with Bax, which in a normal physiological condition, is neutralized by B cell leukemia/lymphoma 2 (Bcl-2) or Bcl-xL. In ischemic state, tBid and Bax interaction leads to mitochondrial membrane depolarization and resultant release of cytochrome $\mathrm{C}$ or apoptosisinducing factor (AIF) into the cytosol. These events initiate caspase-dependent or caspase-independent neuronal death. Released cytochrome $\mathrm{C}$ interacts with pro-caspase 9 and apoptotic protein activating factor-1 (Apaf-1) to form apoptosome that leads to the activation of executor caspases such as caspase-3. In addition, AIF transloacates to the nucleus causing DNA fragmentation and resultant cell death. Further, cell death cascade aggravates due to release of damage associated molecular patterns (DAMPs) by damaged neurons that result in activation of microglia, astrocyte, and endothelial cells and inflammasome formation. These events further orchestrate release of cytokines, ROS, and BBB disruption. In addition, BBB disruption causes influx of peripheral immune cells that exacerbates inflammatory pathways (Fig. 3). Numerous studies both in pre-clinical and clinical platforms are being performed in search of novel therapeutic strategies to either inhibit or slow down pathological mechanisms associated with ischemic stroke (Fig. 4). Though various neuroprotective studies have resulted in frustrating clinical trials, their results also provided us with knowledge on understanding the mechanisms involved in ischemic cascades. However, currently, there remains a pressing need for research and development of stroke therapies that can be successfully replicated in clinical trials for prevention as well as for early critical care in stroke patients.

\section{Conclusion}

Accumulating evidence demonstrates that inflammation plays a key role in the pathogenesis of stroke and it has become an interesting target for therapeutic intervention. However, numerous reports indicate that inflammatory cells are involved in a multiphasic role (beneficial and detrimental) where inhibiting the same pathway at the wrong time could exaggerate the pathogenesis. Hence, a better characterization of stroke pathophysiology with time-defined treatment might provide a definitive protective strategy. Moreover, when basic research is performed using stroke models combined with relevant clinical conditions such as type 2 diabetes, prior infection, and atherosclerosis, there might be successful translation from experimental stroke studies to clinical significance that could pave the way for future successful stroke therapies.

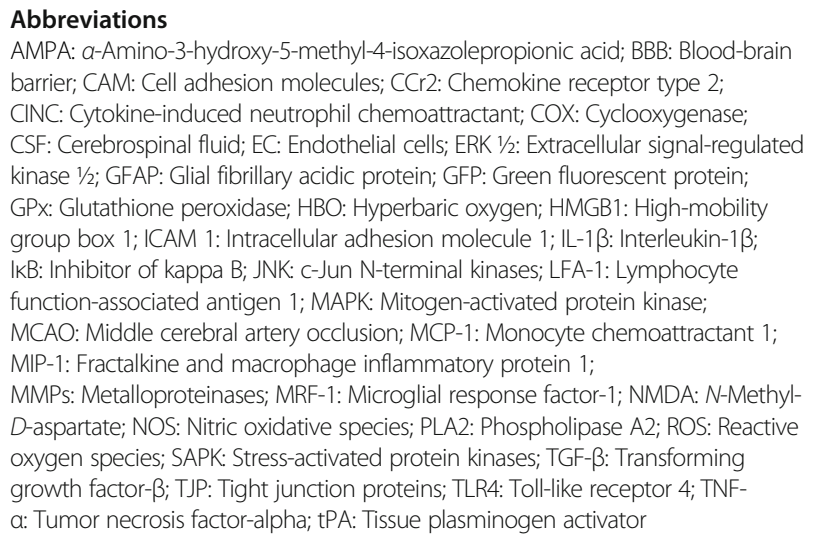

\section{Acknowledgements}

Not applicable

\section{Authors' contributions}

This manuscript was written by RJ. Modifications were suggested by RB. AS, $R B$, FJ, and GR critically edited the final manuscript. All authors read and approved the final manuscript.

\section{Funding}

This work was funded by United Arab Emirates university program for Advanced Research (UPAR 31 M234)

\section{Availability of data and materials \\ Not applicable}

Ethics approval and consent to participate

Not applicable

Consent for publication

Not applicable 


\section{Competing interests}

The authors declare that they have no conflict of interest.

\section{Author details}

'Department of Pharmacology and Therapeutics, College of Medicine and Health Sciences, United Arab Emirates University, Al-Ain, UAE. ${ }^{2}$ Department of Neurology, University of New Mexico Health Sciences Center, Albuquerque, NM 87131, USA.

Received: 26 February 2019 Accepted: 10 June 2019

Published online: 10 July 2019

\section{References}

1. Moskowitz MA, Lo EH, ladecola C. The science of stroke: mechanisms in search of treatments. Neuron. 2010;67(2):181-98.

2. Lallukka T, Ervasti J, Lundström E, Mittendorfer-Rutz E, Friberg E, Virtanen $M$, et al. Trends in diagnosis-specific work disability before and after stroke: a longitudinal population-based study in Sweden. J Am Heart Assoc. 2018; 7(1):e006991.

3. Rammal SA, Almekhlafi MA. Diabetes mellitus and stroke in the Arab world. J Taibah University Med Sci. 2016;11(4):295-300.

4. Feigin $\mathrm{VL}$, Abajobir AA, Abate KH, Abd-Allah F, Abdulle AM, Abera SF, et al. Global, regional, and national burden of neurological disorders during 1990-2015: a systematic analysis for the Global Burden of Disease Study 2015. Lancet Neurol. 2017;16(11):877-97.

5. Catanese L, Tarsia J, Fisher M. Acute ischemic stroke therapy overview. Circulation Research. 2017;120(3):541-58.

6. Dugue R, Nath M, Dugue A, Barone FC. Roles of pro-and anti-inflammatory cytokines in traumatic brain injury and acute ischemic stroke. Mechanisms of Neuroinflammation: IntechOpen; 2017.

7. Khan M, Hashim H, Nisa Z, Kamran S, Alrukn S. thrombolysis for acute ischemic stroke: experience in Dubai, and comparison of Arab with nonArab population. J Neurol Stroke. 2016;4(6):00156.

8. Hajat C, Harrison O, Al Siksek Z. Weqaya: a population-wide cardiovascular screening program in Abu Dhabi, United Arab Emirates. Am J Public Health. 2012;102(5):909-14.

9. Abdulle A, Alnaeemi A, Aljunaibi A, Al Ali A, Al Saedi K, Al Zaabi E, et al. The UAE healthy future study: a pilot for a prospective cohort study of 20,000 United Arab Emirates nationals. BMC Public Health. 2018;18(1):101.

10. Di Carlo A. Human and economic burden of stroke. Age and ageing. 2009; 38(1):4-5.

11. Mishra M, Hedna VS. Neuroinflammation after acute ischemic stroke: a volcano hard to contain. Chinese Journal of Contemporary Neurology and Neurosurgery. 2013;13(11):964-70

12. Jin R, Yang G, Li G. Inflammatory mechanisms in ischemic stroke: role of inflammatory cells. Journal of leukocyte biology. 2010;87(5):779-89.

13. ladecola $C$, Anrather J. The immunology of stroke: from mechanisms to translation. Nature medicine. 2011;17(7):796.

14. Guruswamy R, ElAli A. Complex roles of microglial cells in ischemic stroke pathobiology: new insights and future directions. International journal of molecular sciences. 2017;18(3). https://doi.org/10.3390/ijms18030496.

15. Frank-Cannon TC, Alto LT, McAlpine FE, Tansey MG. Does neuroinflammation fan the flame in neurodegenerative diseases? Molecular neurodegeneration. 2009:4(1):47.

16. Kim JY, Park J, Chang JY, Kim SH, Lee JE. Inflammation after ischemic stroke: the role of leukocytes and glial cells. Experimental neurobiology. 2016;25(5):241-51

17. Emmrich JV, Ejaz S, Neher JJ, Williamson DJ, Baron JC. Regional distribution of selective neuronal loss and microglial activation across the MCA territory after transient focal ischemia: quantitative versus semiquantitative systematic immunohistochemical assessment. J Cereb Blood Flow Metab. 2015;35(1):20-7

18. Ma MW, Wang J, Zhang Q, Wang R, Dhandapani KM, Vadlamudi RK, et al. $\mathrm{NADPH}$ oxidase in brain injury and neurodegenerative disorders. Mol Neurodegener. 2017;12(1):7.

19. Kim JY, Kawabori M, Yenari MA. Innate inflammatory responses in stroke: mechanisms and potential therapeutic targets. Curr Med Chem. 2014;21(18): 2076-97.

20. Sun M, Deng B, Zhao X, Gao C, Yang L, Zhao H, et al. Isoflurane preconditioning provides neuroprotection against stroke by regulating the expression of the TLR4 signalling pathway to alleviate microglial activation. Sci Rep. 2015:5:11445.

21. Jeong HK, Ji K, Min K, Joe EH. Brain inflammation and microglia: facts and misconceptions. Exp Neurobiol. 2013:22(2):59-67.

22. Zhou M, Wang CM, Yang WL, Wang P. Microglial CD14 activated by iNOS contributes to neuroinflammation in cerebral ischemia. Brain Res. 2013;1506:105-14.

23. Facci L, Barbierato M, Marinelli C, Argentini C, Skaper SD, Giusti P. Toll-like receptors $2,-3$ and -4 prime microglia but not astrocytes across central nervous system regions for ATP-Dependent interleukin-1 $\beta$ release. Sci Rep. 2014;4:6824.

24. McDonough A, Lee RV, Noor S, Lee C, Le T, lorga M, et al. Ischemia/ reperfusion induces interferon-stimulated gene expression in microglia. J Neurosci. 2017:37(34):8292-308.

25. Ponomarev ED, Veremeyko T, Weiner HL. MicroRNAs are universal regulators of differentiation, activation, and polarization of microglia and macrophages in normal and diseased CNS. Glia. 2013:61(1):91-103.

26. Parada E, Egea J, Buendia I, Negredo P, Cunha AC, Cardoso S, et al. The microglial a7-acetylcholine nicotinic receptor is a key element in promoting neuroprotection by inducing heme oxygenase-1 via nuclear factor erythroid-2related factor 2. Antioxidants \& redox signaling. 2013:19(11):1135-48.

27. Yuan $Y$, Zha H, Rangarajan P, Ling EA, Wu C. Anti-inflammatory effects of Edaravone and Scutellarin in activated microglia in experimentally induced ischemia injury in rats and in BV-2 microglia. BMC Neurosci. 2014;15:125.

28. Liska GM, Lippert T, Russo E, Nieves N, Borlongan CV. A dual role for hyperbaric oxygen in stroke neuroprotection: preconditioning of the brain and stem cells. Cond Med. 2018;1(4):151-66.

29. Lalancette-Hébert M, Swarup V, Beaulieu JM, Bohacek I, Abdelhamid E, Weng $Y C$, et al. Galectin-3 is required for resident microglia activation and proliferation in response to ischemic injury. J Neurosci. 2012;32(30):10383-95.

30. ElAli A, Jean LeBlanc $\mathrm{N}$. The role of monocytes in ischemic stroke pathobiology: new avenues to explore. Front Aging Neurosci. 2016;8:29.

31. Neumann J, Gunzer M, Gutzeit HO, Ullrich O, Reymann KG, Dinkel K. Microglia provide neuroprotection after ischemia. FASEB J. 2006;20(6):714-6.

32. Denes A, Vidyasagar R, Feng J, Narvainen J, McColl BW, Kauppinen RA, et al. Proliferating resident microglia after focal cerebral ischaemia in mice. J Cereb Blood Flow Metab. 2007;27(12):1941-53.

33. Arumugam TV, Salter JW, Chidlow JH, Ballantyne CM, Kevil CG, Granger DN. Contributions of LFA-1 and Mac-1 to brain injury and microvascular dysfunction induced by transient middle cerebral artery occlusion. Am J Physiol Heart Circ Physiol. 2004;287(6):H2555-H60.

34. Taylor RA, Chang CF, Goods BA, Hammond MD, Mac Grory B, Ai Y, et al. TGF- $\beta 1$ modulates microglial phenotype and promotes recovery after intracerebral hemorrhage. J Clin Invest. 2017;127(1):280-92.

35. Jin WN, Shi SX, Li Z, Li M, Wood K, Gonzales RJ, et al. Depletion of microglia exacerbates postischemic inflammation and brain injury. J Cereb Blood Flow Metab. 2017;37(6):2224-36.

36. Singhal G, Baune BT. Microglia: An interface between the loss of neuroplasticity and depression. Front Cell Neurosci. 2017;11(270).

37. Bylicky MA, Mueller GP, Day RM. Mechanisms of endogenous neuroprotective effects of astrocytes in brain injury. Oxid Med Cell Longev. 2018;2018:6501031.

38. Takano T, Oberheim N, Cotrina ML, Nedergaard M. Astrocytes and ischemic injury. Stroke. 2009;40(3 suppl 1):S8-S12.

39. Ketheeswaranathan P, Turner NA, Spary EJ, Batten TF, McColl BW, Saha S. Changes in glutamate transporter expression in mouse forebrain areas following focal ischemia. Brain Res. 2011:1418:93-103.

40. Hennessy E, Griffin ÉW, Cunningham C. Astrocytes are primed by chronic neurodegeneration to produce exaggerated chemokine and cell infiltration responses to acute stimulation with the cytokines $I L-1 \beta$ and TNF- $a$. J Neurosci. 2015;35(22):8411-22.

41. Wang $H$, Song $G$, Chuang $H$, Chiu C, Abdelmaksoud A, Ye $Y$, et al. Portrait of glial scar in neurological diseases. Int J Immunopathol Pharmacol. 2018;31: 2058738418801406

42. Sykova E. Glial diffusion barriers during aging and pathological states. Prog Brain Res. 2001;132:339-63.

43. Rempe RG, Hartz AMS, Bauer B. Matrix metalloproteinases in the brain and blood-brain barrier: versatile breakers and makers. J Cereb Blood Flow Metab. 2016;36(9):1481-507.

44. Overman JJ, Clarkson AN, Wanner IB, Overman WT, Eckstein I, Maguire JL, et al. A role for ephrin-A5 in axonal sprouting, recovery, and activitydependent plasticity after stroke. Proc Natl Acad Sci U S A. 2012;109(33): E2230-9. 
45. Nowicka D, Rogozinska K, Aleksy M, Witte OW, Skangiel-Kramska J. Spatiotemporal dynamics of astroglial and microglial responses after photothrombotic stroke in the rat brain. Acta Neurobiol Exp. 2008;68(2):155.

46. Endoh M, Maiese $\mathrm{K}$, Wagner J. Expression of the inducible form of nitric oxide synthase by reactive astrocytes after transient global ischemia. Brain Res. 1994;651(1-2):92-100.

47. Li M, Li Z, Yao Y, Jin W-N, Wood K, Liu Q, et al. Astrocyte-derived interleukin-15 exacerbates ischemic brain injury via propagation of cellular immunity. Proc Natl Acad Sci. 2017;114(3):E396-405.

48. Liu Z, Li Y, Cui Y, Roberts C, Lu M, Wilhelmsson U, et al. Beneficial effects of gfap/vimentin reactive astrocytes for axonal remodeling and motor behavioral recovery in mice after stroke. Glia. 2014;62(12):2022-33.

49. Szydlowska K, Zawadzka M, Kaminska B. Neuroprotectant FK506 inhibits glutamate-induced apoptosis of astrocytes in vitro and in vivo. J Neurochem. 2006:99(3):965-75.

50. Dvoriantchikova G, Barakat D, Brambilla R, Agudelo C, Hernandez E, Bethea $J R$, et al. Inactivation of astroglial NF-kappa B promotes survival of retinal neurons following ischemic injury. Eur J Neurosci. 2009;30(2):175-85.

51. Vogelgesang A, Becker KJ, Dressel A. Immunological consequences of ischemic stroke. Acta Neurol Scand. 2014;129(1):1-12.

52. Del Zoppo GJ. The neurovascular unit in the setting of stroke. J Intern Med. 2010;267(2):156-71.

53. Yang $Y$, Rosenberg GA. Matrix metalloproteinases as therapeutic targets for stroke. Brain Res. 2015;1623:30-8.

54. Armulik A, Mäe M, Betsholtz C. Pericytes and the blood-brain barrier: recent advances and implications for the delivery of CNS therapy. Ther Deliv. 2011;2(4):419-22.

55. Fernandez-Klett F, Priller J. Diverse functions of pericytes in cerebral blood flow regulation and ischemia. J Cereb Blood Flow Metab. 2015; 35(6):883-7.

56. ElAli $A$, Thériault $P$, Rivest $S$. The role of pericytes in neurovascular unit remodeling in brain disorders. Int J Mol Sci. 2014;15(4):6453-74.

57. Jansson D, Rustenhoven J, Feng S, Hurley D, Oldfield RL, Bergin PS, et al. A role for human brain pericytes in neuroinflammation. J Neuroinflammation. 2014;11:104.

58. Persidsky Y, Hill J, Zhang M, Dykstra H, Winfield M, Reichenbach NL, et al. Dysfunction of brain pericytes in chronic neuroinflammation. J Cereb Blood Flow Metab. 2016;36(4):794-807.

59. Nakagomi T, Kubo S, Nakano-Doi A, Sakuma R, Lu S, Narita A, et al. Brain vascular pericytes following ischemia have multipotential stem cell activity to differentiate into neural and vascular lineage cells. Stem cells (Dayton, Ohio). 2015;33(6):1962-74.

60. Ozen I, Deierborg T, Miharada K, Padel T, Englund E, Genove G, et al. Brain pericytes acquire a microglial phenotype after stroke. Acta neuropathologica. 2014;128(3):381-96.

61. Sakuma R, Kawahara M, Nakano-Doi A, Takahashi A, Tanaka Y, Narita A, et al. Brain pericytes serve as microglia-generating multipotent vascular stem cells following ischemic stroke. J Neuroinflammation. 2016;13(1):57.

62. Shi Y, Zhang L, Pu H, Mao L, Hu X, Jiang X, et al. Rapid endothelial cytoskeletal reorganization enables early blood-brain barrier disruption and long-term ischaemic reperfusion brain injury. Nat Commun. 2016;7:10523.

63. Dimitrijevic OB, Stamatovic SM, Keep RF, Andjelkovic AV. Effects of the chemokine CCL2 on blood-brain barrier permeability during ischemiareperfusion injury. J Cereb Blood Flow Metab. 2006;26(6):797-810.

64. Candelario-Jalil E. Injury and repair mechanisms in ischemic stroke: considerations for the development of novel neurotherapeutics. Curr Opin Investig Drugs. 2009;10(7):644-54.

65. Ceulemans A-G, Zgavc T, Kooijman R, Hachimi-Idrissi S, Sarre S, Michotte Y. The dual role of the neuroinflammatory response after ischemic stroke: modulatory effects of hypothermia. J Neuroinflammation. 2010;7(1):74.

66. Kleinschnitz C, Blecharz K, Kahles T, Schwarz T, Kraft P, Gobel K, et al. Glucocorticoid insensitivity at the hypoxic blood-brain barrier can be reversed by inhibition of the proteasome. Stroke. 2011;42(4):1081-9.

67. Jiang $X$, Andjelkovic AV, Zhu L, Yang T, Bennett MVL, Chen J, et al. Bloodbrain barrier dysfunction and recovery after ischemic stroke. Prog Neurobiol. 2018;163-164:144-71.

68. Martynov MY, Gusev El. Current knowledge on the neuroprotective and neuroregenerative properties of citicoline in acute ischemic stroke. J Exp Pharmacol. 2015;7:17-28,

69. Jickling GC, Liu D, Ander BP, Stamova B, Zhan X, Sharp FR. Targeting neutrophils in ischemic stroke: translational insights from experimenta studies. J Cereb Blood Flow Metab. 2015;35(6):888-901.
70. Huang L, Wu ZB, Zhuge Q, Zheng W, Shao B, Wang B, et al. Glial scar formation occurs in the human brain after ischemic stroke. International journal of medical sciences. 2014;11(4):344-8.

71. Döring $Y$, Drechsler $M$, Soehnlein O, Weber C. Neutrophils in atherosclerosis. Arteriosclerosis, thrombosis, and vascular biology. 2015;35(2):288-95.

72. Wang $Q$, Tang $X N$, Yenari MA. The inflammatory response in stroke. J Neuroimmunol. 2007;184(1):53-68.

73. Perera MN, Ma HK, Arakawa S, Howells DW, Markus R, Rowe CC, et al. Inflammation following stroke. J Clin Neurosci. 2006;13(1):1-8.

74. Tu X-k, Yang W-z, Shi S-s, Wang C-h, Zhang G-I, Ni T-r, et al. Spatio-temporal distribution of inflammatory reaction and expression of TLR2/4 signaling pathway in rat brain following permanent focal cerebral ischemia. Neurochem Res. 2010:35(8):1147-55.

75. Furlan J, Vergouwen M, Silver F. White blood cell count as a marker of stroke severity and clinical outcomes after acute ischemic stroke (P03.011). Neurology. 2012;78(1 Supplement):P03.011-P03.

76. Yan J, Liu J, Greer JM, McCombe PA. Increased expression of the hypoxiarelated genes in peripheral blood leukocytes of human subjects with acute ischemic stroke. Clin Exp Neuroimmunology. 2014;5(2):216-26.

77. Amantea D, Nappi G, Bernardi G, Bagetta G, Corasaniti MT. Post-ischemic brain damage: pathophysiology and role of inflammatory mediators. FEBS J. 2009;276(1):13-26

78. Kriz J. Inflammation in ischemic brain injury: timing is important. Crit Rev Neurobiol. 2006;18(1-2):145-57.

79. Schilling M, Besselmann M, Leonhard C, Mueller M, Ringelstein EB, Kiefer R. Microglial activation precedes and predominates over macrophage infiltration in transient focal cerebral ischemia: a study in green fluorescent protein transgenic bone marrow chimeric mice. Exp Neurol. 2003;183(1):25-33.

80. Tanaka R, Komine-Kobayashi M, Mochizuki H, Yamada M, Furuya T, Migita M, et al. Migration of enhanced green fluorescent protein expressing bone marrow-derived microglia/macrophage into the mouse brain following permanent focal ischemia. Neuroscience. 2003;117(3):531-9.

81. Price C, Menon D, Peters A, Ballinger J, Barber R, Balan K, et al. Cerebral neutrophil recruitment, histology, and outcome in acute ischemic stroke: an imaging-based study. Stroke. 2004;35(7):1659-64.

82. Buck BH, Liebeskind DS, Saver JL, Bang OY, Yun SW, Starkman S, et al. Early neutrophilia is associated with volume of ischemic tissue in acute stroke. Stroke. 2008:39(2):355-60.

83. Yilmaz G, Granger DN. Cell adhesion molecules and ischemic stroke. Neurol Res. 2008:30(8):783-93.

84. Yang Y, Jalal FY, Thompson JF, Walker EJ, Candelario-Jalil E, Li L, et al. Tissue inhibitor of metalloproteinases-3 mediates the death of immature oligodendrocytes via TNF-a/TACE in focal cerebral ischemia in mice. J Neuroinflammation. 2011;8(1):108

85. Zinnhardt B, Viel T, Wachsmuth L, Vrachimis A, Wagner S, Breyholz HJ, et al. Multimodal imaging reveals temporal and spatial microglia and matrix metalloproteinase activity after experimental stroke. J Cereb Blood Flow Metab. 2015;35(11):1711-21.

86. Yang Y, Hill JW, Rosenberg GA. Multiple roles of metalloproteinases in neurological disorders. Prog Mol Biol Transl Sci. 2011;99: Elsevier:241-63.

87. Taylor RA, Sansing LH. Microglial responses after ischemic stroke and intracerebral hemorrhage. Clin Dev Immunol. 2013;2013:746068.

88. Gülke $\mathrm{E}$, Gelderblom M, Magnus T. Danger signals in stroke and their role on microglia activation after ischemia. Ther Adv Neurol Disord. 2018;11: 1756286418774254 .

89. Zhao SC, Ma LS, Chu ZH, Xu H, Wu WQ, Liu F. Regulation of microglial activation in stroke. Acta Pharmacol Sin. 2017;38(4):445-58.

90. Mracsko E, Javidi E, Na S-Y, Kahn A, Liesz A, Veltkamp R. Leukocyte invasion of the brain after experimental intracerebral hemorrhage in mice. Stroke. 2014:45(7):2107-14.

91. Schilling M, Besselmann M, Müller M, Strecker JK, Ringelstein EB, Kiefer R. Predominant phagocytic activity of resident microglia over hematogenous macrophages following transient focal cerebral ischemia: an investigation using green fluorescent protein transgenic bone marrow chimeric mice. Exp Neurol. 2005;196(2):290-7.

92. Schilling $M$, Strecker J-K, Schäbitz W-R, Ringelstein E, Kiefer R. Effects of monocyte chemoattractant protein 1 on blood-borne cell recruitment after transient focal cerebral ischemia in mice. Neuroscience. 2009;161(3):806-12.

93. Breckwoldt MO, Chen JW, Stangenberg L, Aikawa E, Rodriguez E, Qiu S, et al. Tracking the inflammatory response in stroke in vivo by sensing the enzyme myeloperoxidase. Proc Natl Acad Sci. 2008;105(47):18584-9. 
94. Kokovay E, Li L, Cunningham LA. Angiogenic recruitment of pericytes from bone marrow after stroke. J Cereb Blood Flow Metab. 2006;26(4):545-55.

95. Kronenberg G, Uhlemann R, Richter N, Klempin F, Wegner S, Staerck L, et al. Distinguishing features of microglia- and monocyte-derived macrophages after stroke. Acta neuropathologica. 2018;135(4):551-68.

96. Weston RM, Jones NM, Jarrott B, Callaway JK. Inflammatory cell infiltration after endothelin-1-induced cerebral ischemia: histochemical and myeloperoxidase correlation with temporal changes in brain injury. J Cereb Blood Flow Metab. 2007;27(1):100-14.

97. Watcharotayangul J, Mao L, Xu H, Vetri F, Baughman VL, Paisansathan C, et al. Post-ischemic vascular adhesion protein-1 inhibition provides neuroprotection in a rat temporary middle cerebral artery occlusion model. J Neurochem. 2012;123(Suppl 2):116-24.

98. Perez-de-Puig I, Miró-Mur F, Ferrer-Ferrer M, Gelpi E, Pedragosa J, Justicia C, et al. Neutrophil recruitment to the brain in mouse and human ischemic stroke. Acta Neuropathol. 2015;129(2):239-57.

99. Gelderblom M, Leypoldt F, Steinbach K, Behrens D, Choe C-U, Siler DA, et al. Temporal and spatial dynamics of cerebral immune cell accumulation in stroke. Stroke. 2009;40(5):1849-57.

100. Jin G, Tsuji K, Xing C, Yang Y-G, Wang X, Lo EH. CD47 gene knockout protects against transient focal cerebral ischemia in mice. Exp Neurol. 2009; 217(1):165-70.

101. Tsai NW, Chang WN, Shaw CF, Jan CR, Lu CH. Leucocyte apoptosis in patients with acute ischaemic stroke. Clin Exp Pharmacol Physiol. 2010; 37(9):884-8

102. Gokhan S, Ozhasenekler A, Mansur Durgun H, Akil E, Ustundag M, Orak M. Neutrophil lymphocyte ratios in stroke subtypes and transient ischemic attack. Eur Rev Med Pharmacol Sci. 2013;17(5):653-7.

103. Feng Y, Liao S, Wei C, Jia D, Wood K, Liu Q, et al. Infiltration and persistence of lymphocytes during late-stage cerebral ischemia in middle cerebral artery occlusion and photothrombotic stroke models. J Neuroinflammation. 2017; 14(1):248.

104. Jander S, Kraemer M, Schroeter M, Witte OW, Stoll G. Lymphocytic infiltration and expression of intercellular adhesion molecule-1 in photochemically induced ischemia of the rat cortex. J Cereb Blood Flow Metab. 1995;15(1):42-51.

105. Yilmaz G, Arumugam TV, Stokes KY, Granger DN. Role of T lymphocytes and interferon- $\gamma$ in ischemic stroke. Circulation. 2006;113(17):2105-12.

106. Hum PD, Subramanian S, Parker SM, Afentoulis ME, Kaler LJ, Vandenbark $A A$, et al. T-and B-cell-deficient mice with experimental stroke have reduced lesion size and inflammation. J Cereb Blood Flow Metab. 2007; 27(11):1798-805.

107. Xie L, Yang SH. Interaction of astrocytes and T cells in physiological and pathological conditions. Brain Res. 2015;1623:63-73.

108. Liesz A, Suri-Payer E, Veltkamp C, Doerr H, Sommer C, Rivest S, et al. Regulatory $T$ cells are key cerebroprotective immunomodulators in acute experimental stroke. Nat Med. 2009;15(2):192-9.

109. Ren $X$, Akiyoshi $K$, Vandenbark AA, Hurn PD, Offner H. CD4+FoxP3+ regulatory T-cells in cerebral ischemic stroke. Metab Brain Dis. 2011;26(1):87-90.

110. Kleinschnitz C, Kraft P, Dreykluft A, Hagedorn I, Gobel K, Schuhmann MK et al. Regulatory $T$ cells are strong promoters of acute ischemic stroke in mice by inducing dysfunction of the cerebral microvasculature. Blood. 2013; 121(4):679-91.

111. Sinning C, Westermann D, Clemmensen P. Oxidative stress in ischemia and reperfusion: current concepts, novel ideas and future perspectives. Biomark Med. 2017;11(11):11031-40

112. Van Hemelrijck A, Hachimi-Idrissi S, Sarre S, Ebinger G, Michotte Y. Postischaemic mild hypothermia inhibits apoptosis in the penumbral region by reducing neuronal nitric oxide synthase activity and thereby preventing endothelin-1-induced hydroxyl radical formation. Eur J Neurosci. 2005;22(6): 1327-37.

113. Shirley R, Ord EN, Work LM. Oxidative stress and the use of antioxidants in stroke. Antioxidants (Basel, Switzerland). 2014;3(3):472-501.

114. Chen ZQ, Mou RT, Feng DX, Wang Z, Chen G. The role of nitric oxide in stroke. Med Gas Res. 2017;7(3):194-203.

115. Liu P, Xu B, Hock CE, Nagele R, Sun FF, Wong PY. NO modulates P-selectin and ICAM-1 mRNA expression and hemodynamic alterations in hepatic I/R Am J Physiol. 1998;275(6):H2191-H8.

116. Lundblad C, Grände P-O, Bentzer P. Hemodynamic and histological effects of traumatic brain injury in eNOS-deficient mice. J Neurotrauma. 2009; 26(11):1953-62.
117. Garcia-Bonilla L, Moore JM, Racchumi G, Zhou P, Butler JM, ladecola C, et al. Inducible nitric oxide synthase in neutrophils and endothelium contributes to ischemic brain injury in mice. J Immunol. 2014;193(5):2531-7.

118. Li W, Yang S. Targeting oxidative stress for the treatment of ischemic stroke: upstream and downstream therapeutic strategies. Brain Circulation. 2016; 2(4):153-63.

119. van der Worp HB, Bar PR, Kappelle L, de Wildt DJ. Dietary vitamin E levels affect outcome of permanent focal cerebral ischemia in rats. Stroke. 1998; 29(5):1002-5 discussion 5-6.

120. Garcia-Estrada J, Gonzalez-Perez O, Gonzalez-Castaneda RE, MartinezContreras A, Luquin S, de la Mora PG, et al. An alpha-lipoic acid-vitamin E mixture reduces post-embolism lipid peroxidation, cerebral infarction, and neurological deficit in rats. Neurosci Res. 2003:47(2):219-24.

121. van der Worp HB, Thomas CE, Kappelle LJ, Hoffman WP, de Wildt DJ, Bar PR Inhibition of iron-dependent and ischemia-induced brain damage by the alpha-tocopherol analogue MDL 74,722. Exp Neurol. 1999;155(1):103-8.

122. Ascherio A, Rimm EB, Hernan MA, Giovannucci E, Kawachi I, Stampfer MJ, et al. Relation of consumption of vitamin $E$, vitamin $C$, and carotenoids to risk for stroke among men in the United States. Annals of internal medicine. 1999;130(12):963-70

123. Rabadi MH, Kristal BS. Effect of vitamin C supplementation on stroke recovery: a case-control study. Clinical interventions in aging. 2007;2(1):147-51.

124. Schürks M, Glynn RJ, Rist PM, Tzourio C, Kurth T. Effects of vitamin E on stroke subtypes: meta-analysis of randomised controlled trials. BMJ. 2010; 341:c5702.

125. Kato N, Yanaka K, Nagase S, Hirayama A, Nose T. The antioxidant EPC-K1 ameliorates brain injury by inhibiting lipid peroxidation in a rat model of transient focal cerebral ischaemia. Acta neurochirurgica. 2003:145(6):489-93 discussion 93.

126. Yamamoto S, Hagiwara S, Hidaka S, Shingu C, Goto K, Kashima K, et al. The antioxidant EPC-K1 attenuates renal ischemia-reperfusion injury in a rat model. American Journal of Nephrology. 2011;33(6):485-90.

127. Antonic A, Dottori M, Macleod MR, Donnan GA, Howells DW. NXY-059, failed stroke neuroprotectant, offers no protection to stem cell-derived human neurons. J Stroke Cerebrovasc Dis. 2018;27(8):2158-65.

128. van der Worp HB, Kappelle LJ, Algra A, Bär PR, Orgogozo JM, Ringelstein EB, et al. The effect of tirilazad mesylate on infarct volume of patients with acute ischemic stroke. Neurology. 2002;58(1):133-5.

129. Watanabe K, Tanaka M, Yuki S, Hirai M, Yamamoto Y. How is edaravone effective against acute ischemic stroke and amyotrophic lateral sclerosis? J Clin Biochem Nutr. 2018;62(1):20-38.

130. Toyoda K, Fujii K, Kamouchi M, Nakane H, Arihiro S, Okada Y, et al. Free radical scavenger, edaravone, in stroke with internal carotid artery occlusion. J Neurol Sci. 2004:221(1-2):11-7.

131. Clark WM. Efficacy of citicoline as an acute stroke treatment. Expert opinion on pharmacotherapy. 2009;10(5):839-46.

132. Grieb P. Neuroprotective properties of citicoline: facts, doubts and unresolved issues. CNS drugs. 2014;28(3):185-93.

133. Rajah GB, Ding Y. Experimental neuroprotection in ischemic stroke: a concise review. Neurosurgical focus. 2017:42(4):E2.

134. Alvarez-Sabin J, Roman GC. The role of citicoline in neuroprotection and neurorepair in ischemic stroke. Brain Sci. 2013;3(3):1395-414.

135. Davalos A, Alvarez-Sabin J, Castillo J, Diez-Tejedor E, Ferro J, Martinez-Vila E, et al. Citicoline in the treatment of acute ischaemic stroke: an international, randomised, multicentre, placebo-controlled study (ICTUS trial). Lancet (London, England). 2012;380(9839):349-57.

136. Secades JJ, Alvarez-Sabin J, Castillo J, Diez-Tejedor E, Martinez-Vila E, Rios J, et al. Citicoline for acute ischemic stroke: a systematic review and formal meta-analysis of randomized, double-blind, and placebo-controlled trials. J Stroke Cerebrovasc Dis. 2016;25(8):1984-96.

137. Shi PY, Zhou XC, Yin XX, Xu LL, Zhang XM, Bai HY. Early application of citicoline in the treatment of acute stroke: a meta-analysis of randomized controlled trials. J Huazhong Univ Sci Technolog Med Sci. 2016;36(2):270-7.

138. Overgaard K. The effects of citicoline on acute ischemic stroke: a review. J Stroke Cerebrovasc Dis. 2014;23(7):1764-9.

139. Stolp HB. Neuropoietic cytokines in normal brain development and neurodevelopmental disorders. Molecular and cellular neurosciences. 2013:53:63-8.

140. Lakhan SE, Kirchgessner A, Hofer M. Inflammatory mechanisms in ischemic stroke: therapeutic approaches. J Translational Med. 2009:7(1):97.

141. Reyes R, Cardeñes B, Machado-Pineda Y, Cabañas C. Tetraspanin CD9: A key regulator of cell adhesion in the immune system. Frontiers in Immunology. 2018;9(863). https://doi.org/10.3389/fimmu.2018.00863. 
142. Sairanen T, Carpén O, Karjalainen-Lindsberg M-L, Paetau A, Turpeinen U, Kaste $\mathrm{M}$, et al. Evolution of cerebral tumor necrosis factor-a production during human ischemic stroke. Stroke. 2001;32(8):1750-8.

143. He H-Y, Ren L, Guo T, Deng Y-H. Neuronal autophagy aggravates microglial inflammatory injury by downregulating CX3CL1/fractalkine after ischemic stroke. Neural Regeneration Research. 2019;14(2):280-8.

144. Lai AY, Todd KG. Microglia in cerebral ischemia: molecular actions and interactions. Canadian journal of physiology and pharmacology. 2006; 84(1):49-59.

145. Disdier C, Chen X, Kim JE, Threlkeld SW, Stonestreet BS. Anti-cytokine therapy to attenuate ischemic-reperfusion associated brain injury in the perinatal period. Brain Sci. 2018;8(6). https://doi.org/10.3390/ brainsci8060101.

146. Yang C, Hawkins KE, Doré S, Candelario-Jalil E. Neuroinflammatory mechanisms of blood-brain barrier damage in ischemic stroke. American Journal of Physiology-Cell Physiology. 2019;316(2):C135-C53.

147. Ramiro L, Simats A, García-Berrocoso T, Montaner J. Inflammatory molecules might become both biomarkers and therapeutic targets for stroke management. Therapeutic advances in neurological disorders. 2018;11: 1756286418789340 .

148. Dziewulska D, Mossakowski MJ. Cellular expression of tumor necrosis factor $a$ and its receptors in human ischemic stroke. Clinical neuropathology. 2003; 22(1):35-40.

149. Zaremba J, Losy J. Early TNF-alpha levels correlate with ischaemic stroke severity. Acta Neurol Scand. 2001;104(5):288-95.

150. Sobowale OA, Parry-Jones AR, Smith CJ, Tyrrell PJ, Rothwell NJ, Allan SM. Interleukin-1 in stroke. Stroke. 2016:47(8):2160-7.

151. Lambertsen KL, Biber K, Finsen B. Inflammatory cytokines in experimental and human stroke. J Cereb Blood Flow Metab. 2012;32(9):1677-98.

152. Ormstad H, Aass HCD, Lund-Sørensen N, Amthor K-F, Sandvik L. Erratum to: Serum levels of cytokines and C-reactive protein in acute ischemic stroke patients, and their relationship to stroke lateralization, type, and infarct volume. Journal of Neurology. 2012;259(2):400

153. Tarkowski E, Rosengren L, Blomstrand C, Wikkelso C, Jensen C, Ekholm S, et al. Early intrathecal production of interleukin-6 predicts the size of brain lesion in stroke. Stroke. 1995:26(8):1393-8.

154. Waje-Andreassen U, Krakenes J, Ulvestad E, Thomassen L, Myhr KM, Aarseth J, et al. IL-6: an early marker for outcome in acute ischemic stroke. Acta Neurol Scand. 2005;111(6):360-5.

155. Gredal H, Thomsen BB, Boza-Serrano A, Garosi L, Rusbridge C, Anthony D, et al. Interleukin- 6 is increased in plasma and cerebrospinal fluid of community-dwelling domestic dogs with acute ischaemic stroke. Neuroreport. 2017;28(3):134-40.

156. Singh N, Hopkins SJ, Hulme S, Galea JP, Hoadley M, Vail A, et al. The effect of intravenous interleukin-1 receptor antagonist on inflammatory mediators in cerebrospinal fluid after subarachnoid haemorrhage: a phase II randomised controlled trial. Journal of neuroinflammation. 2014;11(1). https://doi.org/10.1186/1742-2094-11-1.

157. Cekanaviciute E, Fathali N, Doyle KP, Williams AM, Han J, Buckwalter MS. Astrocytic transforming growth factor-beta signaling reduces subacute neuroinflammation after stroke in mice. Glia. 2014;62(8):1227-40.

158. Doll DN, Barr TL, Simpkins JW. Cytokines: their role in stroke and potential use as biomarkers and therapeutic targets. Aging and disease. 2014;5(5):294-306

159. Ransohoff RM, Trettel F. Editorial Research Topic "Chemokines and chemokine receptors in brain homeostasis". Frontiers in Cellular Neuroscience. 2015;9(132). https://doi.org/10.3389/fncel.2015.00132.

160. Raman D, Sobolik-Delmaire T, Richmond A. Chemokines in health and disease. Experimental cell research. 2011;317(5):575-89.

161. Murphy PM. Chemokines and chemokine receptors. Clinical Immunology: Elsevier. 2019;e1:157-70.

162. Hughes CE, Nibbs RJB. A guide to chemokines and their receptors. The FEBS Journal. 2018;285(16):2944-71.

163. Mennicken F, Maki R, de Souza EB, Quirion R. Chemokines and chemokine receptors in the CNS: a possible role in neuroinflammation and patterning Trends in pharmacological sciences. 1999;20(2):73-8.

164. Bacon KB, Harrison JK. Chemokines and their receptors in neurobiology: perspectives in physiology and homeostasis. Journal of neuroimmunology. 2000;104(1):92-7.

165. Vidale S, Consoli A, Arnaboldi M, Consoli D. Postischemic Inflammation in Acute Stroke. Journal of clinical neurology (Seoul, Korea). 2017;13(1):1-9.
166. Brait VH, Rivera J, Broughton BR, Lee S, Drummond GR, Sobey CG. Chemokine-related gene expression in the brain following ischemic stroke: no role for CXCR2 in outcome. Brain research. 2011;1372:169-79.

167. Hughes PM, Allegrini PR, Rudin M, Perry VH, Mir AK, Wiessner C. Monocyte chemoattractant protein-1 deficiency is protective in a murine stroke model. J Cereb Blood Flow Metab. 2002;22(3):308-17.

168. Fang W, Zhai X, Han D, Xiong X, Wang T, Zeng X, et al. CCR2-dependent monocytes/macrophages exacerbate acute brain injury but promote functional recovery after ischemic stroke in mice. Theranostics. 2018;8(13): 3530-43.

169. Dimitrijevic OB, Stamatovic SM, Keep RF, Andjelkovic AV. Absence of the chemokine receptor CCR2 protects against cerebral ischemia/reperfusion injury in mice. Stroke. 2007;38(4):1345-53.

170. Guo YQ, Zheng LN, Wei JF, Hou XL, Yu SZ, Zhang WW, et al. Expression of CCL2 and CCR2 in the hippocampus and the interventional roles of propofol in rat cerebral ischemia/reperfusion. Experimental and therapeutic medicine. 2014;8(2):657-61.

171. García-Berrocoso T, Giralt D, Llombart V, Bustamante A, Penalba A, Flores A, et al. Chemokines after human ischemic stroke: From neurovascular unit to blood using protein arrays. Translational Proteomics. 2014;3:1-9.

172. Hammond MD, Taylor RA, Mullen MT, Ai Y, Aguila HL, Mack M, et al. CCR2+ Ly6C(hi) inflammatory monocyte recruitment exacerbates acute disability following intracerebral hemorrhage. J Neurosci. 2014;34(11):3901-9.

173. Wattananit S, Tornero D, Graubardt N, Memanishvili T, Monni E, Tatarishvili J, et al. Monocyte-derived macrophages contribute to spontaneous long-term functional recovery after stroke in mice. J Neurosci. 2016;36(15):4182-95.

174. Greenhalgh AD, Zarruk JG, Healy LM, Baskar Jesudasan SJ, Jhelum P, Salmon CK, et al. Peripherally derived macrophages modulate microglial function to reduce inflammation after CNS injury. PLoS biology. 2018;16(10):e2005264.

175. Gliem M, Mausberg AK, Lee Jl, Simiantonakis I, van Rooijen N, Hartung HP, et al. Macrophages prevent hemorrhagic infarct transformation in murine stroke models. Annals of neurology. 2012;71(6):743-52

176. Terao Y, Ohta H, Oda A, Nakagaito Y, Kiyota Y, Shintani Y. Macrophage inflammatory protein-3alpha plays a key role in the inflammatory cascade in rat focal cerebral ischemia. Neuroscience research. 2009;64(1):75-82.

177. Liu X, Liu J, Zhao S, Zhang H, Cai W, Cai M, et al. Interleukin-4 is essential for microglia/macrophage $\mathrm{M} 2$ polarization and long-term recovery after cerebral ischemia. Stroke. 2016;47(2):498-504.

178. Bajetto A, Bonavia R, Barbero S, Florio T, Schettini G. Chemokines and their receptors in the central nervous system. Frontiers in neuroendocrinology. 2001;22(3):147-84

179. Ransohoff RM. Chemokines and chemokine receptors: standing at the crossroads of immunobiology and neurobiology. Immunity. 2009;31(5):711-21.

180. Leick M, Azcutia V, Newton G, Luscinskas FW. Leukocyte recruitment in inflammation: basic concepts and new mechanistic insights based on new models and microscopic imaging technologies. Cell and tissue research. 2014:355(3):647-56.

181. Chen Y, Hallenbeck JM, Ruetzler C, Bol D, Thomas K, Berman NE, et al. Overexpression of monocyte chemoattractant protein 1 in the brain exacerbates ischemic brain injury and is associated with recruitment of inflammatory cells. J Cereb Blood Flow Metab. 2003;23(6):748-55.

182. Kim JS, Gautam SC, Chopp M, Zaloga C, Jones ML, Ward PA, et al Expression of monocyte chemoattractant protein-1 and macrophage inflammatory protein-1 after focal cerebral ischemia in the rat. Journal of neuroimmunology. 1995;56(2):127-34.

183. Chu HX, Arumugam TV, Gelderblom M, Magnus T, Drummond GR, Sobey CG. Role of CCR2 in inflammatory conditions of the central nervous system. J Cereb Blood Flow Metab. 2014;34(9):1425-9.

184. Stamatovic SM, Shakui P, Keep RF, Moore BB, Kunkel SL, Van Rooijen N, et al Monocyte chemoattractant protein-1 regulation of blood-brain barrier permeability. J Cereb Blood Flow Metab. 2005;25(5):593-606.

185. Barone FC, Feuerstein GZ. Inflammatory mediators and stroke: new opportunities for novel therapeutics. Journal of Cerebral Blood Flow \& Metabolism. 1999:19(8):819-34.

186. Willard SS, Koochekpour S. Glutamate, glutamate receptors, and downstream signaling pathways. Int J Biol Sci. 2013;9(9):948-59.

187. Mázala DA, Grange RW, Chin ER. The role of proteases in excitationcontraction coupling failure in muscular dystrophy. Am J Physiol Cell Physiol. 2015;308(1):C33-40.

188. Weber JT. Altered calcium signaling following traumatic brain injury. Frontiers in pharmacology. 2012;3:60. 
189. Tymianski M, Charlton MP, Carlen PL, Tator CH. Source specificity of early calcium neurotoxicity in cultured embryonic spinal neurons. J Neurosci. 1993;13(5):2085-104.

190. Sattler R, Tymianski M. Molecular mechanisms of glutamate receptor-mediated excitotoxic neuronal cell death. Molecular neurobiology. 2001;24(1-3):107-29.

191. Xu J, Kurup P, Zhang Y, Goebel-Goody SM, Wu PH, Hawasli AH, et al. Extrasynaptic NMDA receptors couple preferentially to excitotoxicity via calpain-mediated cleavage of STEP. J Neurosci. 2009;29(29):9330-43.

192. Casas Al, Kleikers PWM, Geuss E, Langhauser F, Egea J, Lopez MG, et al. Calcium-dependent reactive oxygen formation and blood-brain barrier breakdown by NOX5 limits post-reperfusion outcome in stroke. bioRxiv. 2018:359893. https://doi.org/10.1101/359893

193. Liu F, Lu J, Manaenko A, Tang J, Hu Q. Mitochondria in ischemic stroke: new insight and implications. Aging and disease. 2018;9(5):924-37.

194. Zhu J, Xu S, Li S, Yang X, Yu X, Zhang X. Up-regulation of GluN2Acontaining NMDA receptor protects cultured cortical neuron cells from oxidative stress. Heliyon. 2018;4(11):e00976-e.

195. Wu QJ, Tymianski M. Targeting NMDA receptors in stroke: new hope in neuroprotection. Molecular brain. 2018;11(1):15.

196. Zhou L, Li F, Xu HB, Luo CX, Wu HY, Zhu MM, et al. Treatment of cerebral ischemia by disrupting ischemia-induced interaction of nNOS with PSD-95. Nat Med. 2010;16(12):1439-43.

197. Lee H-J, Zheng JJ. PDZ domains and their binding partners: structure, specificity, and modification. Cell Communication and Signaling. 2010;8(1):8.

198. Sattler R, Xiong Z, Lu WY, Hafner M, MacDonald JF, Tymianski M. Specific coupling of NMDA receptor activation to nitric oxide neurotoxicity by PSD95 protein. Science (New York, NY). 1999;284(5421):1845-8.

199. Cook DJ, Teves L, Tymianski M. Treatment of stroke with a PSD-95 inhibitor in the gyrencephalic primate brain. Nature. 2012;483(7388):213-7.

200. Chen Y, Brennan-Minnella AM, Sheth S, El-Benna J, Swanson RA. Tat-NR2B9C prevents excitotoxic neuronal superoxide production. J Cereb Blood Flow Metab. 2015;35(5):739-42.

201. Teves LM, Cui H, Tymianski M. Efficacy of the PSD95 inhibitor Tat-NR2B9c in mice requires dose translation between species. J Cereb Blood Flow Metab. 2016;36(3):555-61.

202. Hill MD, Martin RH, Mikulis D, Wong JH, Silver FL, Terbrugge KG, et al. Safety and efficacy of NA-1 in patients with iatrogenic stroke after endovascular aneurysm repair (ENACT): a phase 2, randomised, double-blind, placebocontrolled trial. The Lancet Neurology. 2012;11(11):942-50.

203. Luo C-X, Lin Y-H, Qian X-D, Tang Y, Zhou H-H, Jin X, et al. Interaction of nNOS with PSD-95 negatively controls regenerative repair after stroke. The Journal of Neuroscience. 2014;34(40):13535-48.

204. Lai TW, Zhang S, Wang YT. Excitotoxicity and stroke: identifying novel targets for neuroprotection. Progress in Neurobiology. 2014;115:157-88.

205. Bach A, Pedersen SW, Dorr LA, Vallon G, Ripoche I, Ducki S, et al. Biochemical investigations of the mechanism of action of small molecules ZL006 and IC87201 as potential inhibitors of the nNOS-PDZ/PSD-95-PDZ interactions. Scientific Reports. 2015;5:12157.

206. Hong JM, Choi MH, Sohn S-I, Hwang Y-H, Ahn SH, Lee Y-B, et al. Safety and optimal neuroprotection of neu2000 in acute ischemic stroke with reCanalization: study protocol for a randomized, double-blinded, placebocontrolled, phase-II trial. Trials. 2018;19(1):375.

207. Cho SI, Park UJ, Chung JM, Gwag BJ. Neu2000, an NR2B-selective, moderate NMDA receptor antagonist and potent spin trapping molecule for stroke. Drug news \& perspectives. 2010;23(9):549-56.

208. Fujikawa DG. The role of excitotoxic programmed necrosis in acute brain injury. Computational and structural biotechnology journal. 2015;13:212-21.

209. Taylor DL, Jones F, Kubota ESCS, Pocock JM. Stimulation of microglial metabotropic glutamate receptor mGlu2 triggers tumor necrosis factor ainduced neurotoxicity in concert with microglial-derived Fas ligand. Journal of Neuroscience. 2005;25(11):2952-64.

210. Tan HK, Heywood D, Ralph GS, Bienemann A, Baker AH, Uney JB. Tissue inhibitor of metalloproteinase 1 inhibits excitotoxic cell death in neurons. Molecular and Cellular Neuroscience. 2003;22(1):98-106.

211. Vandooren J, Van Damme J, Opdenakker G. On the structure and functions of gelatinase B/matrix metalloproteinase-9 in neuroinflammation. Progress in brain research. 2014;214: Elsevier:193-206.

212. Morancho A, Rosell A, García-Bonilla L, Montaner J. Metalloproteinase and stroke infarct size: role for anti-inflammatory treatment? Annals of the New York Academy of Sciences. 2010;1207(1):123-33.
213. Park KP, Rosell A, Foerch C, Xing C, Kim WJ, Lee S, et al. Plasma and brain matrix metalloproteinase-9 after acute focal cerebral ischemia in rats. Stroke. 2009;40(8):2836-42.

214. Rosenberg GA. Matrix metalloproteinases in neuroinflammation. Glia. 2002; 39(3):279-91.

215. Gasche Y, Soccal PM, Kanemitsu M, Copin J-C. Matrix metalloproteinases and diseases of the central nervous system with a special emphasis on ischemic brain. Front Biosci. 2006;11(5):1289-301.

216. Golab P, Kielbus M, Bielewicz J, Kurzepa J. The effect of recombinant tissue plasminogen activator on MMP-2 and MMP-9 activities in vitro. Neurological research. 2015;37(1):9-13.

217. Rosenberg G, Estrada E, Dencoff J. Matrix metalloproteinases and TIMPs are associated with blood-brain barrier opening after reperfusion in rat brain. Stroke. 1998;29(10):2189-95.

218. Kurzepa J, Kurzepa J, Golab P, Czerska S, Bielewicz J. The significance of matrix metalloproteinase (MMP)-2 and MMP-9 in the ischemic stroke. Int J Neurosci. 2014;124(10):707-16.

219. Lenglet S, Montecucco F, Mach F, Schaller K, Gasche Y, Copin J-C. Analysis of the expression of nine secreted matrix metalloproteinases and their endogenous inhibitors in the brain of mice subjected to ischaemic stroke. Thrombosis and haemostasis. 2014;112(02):363-78.

220. Cuadrado E, Rosell A, Borrell-Pagès M, García-Bonilla L, Hernández-Guillamon $M$, Ortega-Aznar A, et al. Matrix metalloproteinase-13 is activated and is found in the nucleus of neural cells after cerebral ischemia. Journal of Cerebral Blood Flow \& Metabolism. 2009;29(2):398-410.

221. Amantea D, Certo M, Russo R, Bagetta G, Corasaniti MT, Tassorelli C. Early reperfusion injury is associated to MMP2 and IL-1 $\beta$ elevation in cortical neurons of rats subjected to middle cerebral artery occlusion. Neuroscience. 2014;277:755-63.

222. Orbe J, Barrenetxe J, Rodriguez JA, Vivien D, Orset C, Parks W, et al. Matrix metalloproteinase-10 effectively reduces infarct size in experimental stroke by enhancing fibrinolysis via a thrombin-activatable fibrinolysis inhibitormediated mechanism. Circulation. 2011:CIRCULATIONAHA. 111.047100.

223. Dang B, Duan X, Wang Z, He W, Chen G. A therapeutic target of cerebral hemorrhagic stroke: matrix metalloproteinase- 9. Current drug targets. 2017; 18(12):1358-66.

224. Montaner J, Alvarez-Sabín J, Molina C, Anglés A, Abilleira S, Arenillas J, et al. Matrix metalloproteinase expression after human cardioembolic stroke: temporal profile and relation to neurological impairment. Stroke. 2001;32(8):1759-66.

225. Ma F, Rodriguez S, Buxo X, Morancho A, Riba-Llena I, Carrera A, et al. Plasma matrix metalloproteinases in patients with stroke during intensive rehabilitation therapy. Archives of physical medicine and rehabilitation. 2016;97(11):1832-40.

226. Abdelnaseer MM, Elfauomy NM, Esmail EH, Kamal MM, Elsawy EH. Matrix metalloproteinase-9 and recovery of acute ischemic stroke. Journal of Stroke and Cerebrovascular Diseases. 2017;26(4):733-40.

227. Steenport M, Khan KM, Du B, Barnhard SE, Dannenberg AJ, Falcone DJ. Matrix metalloproteinase (MMP)-1 and MMP-3 induce macrophage MMP-9: evidence for the role of TNF-alpha and cyclooxygenase-2. Journal of immunology (Baltimore, Md : 1950). 2009;183(12):8119-27.

228. Stanimirovic D, Satoh K. Inflammatory mediators of cerebral endothelium: a role in ischemic brain inflammation. Brain Pathology. 2000;10(1):113-26.

229. Tabuchi S, Uozumi N, Ishii S, Shimizu Y, Watanabe T, Shimizu T. Mice deficient in cytosolic phospholipase A2 are less susceptible to cerebral ischemia/reperfusion injury. Vienna: Springer Vienna; 2003.

230. Rouzer CA, Marnett LJ. Cyclooxygenases: structural and functional insights. Journal of lipid research. 2009;50 Suppl:S29-34.

231. Iadecola C, Sugimoto K, Niwa K, Kazama K, Ross ME. Increased susceptibility to ischemic brain injury in cyclooxygenase-1-deficient mice. J Cereb Blood Flow Metab. 2001;21(12):1436-41.

232. Candelario-Jalil E, González-Falcón A, García-Cabrera M, Álvarez D, Al-Dalain $\mathrm{S}$, Martínez $\mathrm{G}$, et al. Assessment of the relative contribution of COX-1 and COX-2 isoforms to ischemia-induced oxidative damage and neurodegeneration following transient global cerebral ischemia. Journal of neurochemistry. 2003;86(3):545-55.

233. Chen C, Bazan NG. Lipid signaling: sleep, synaptic plasticity, and neuroprotection. Prostaglandins \& other lipid mediators. 2005;77(1-4):65-76.

234. Niwa K, Araki E, Morham SG, Ross ME, ladecola C. Cyclooxygenase-2 contributes to functional hyperemia in whisker-barrel cortex. Journal of Neuroscience. 2000;20(2):763-70.

235. Minghetti L. Cyclooxygenase-2 (COX-2) in inflammatory and degenerative brain diseases. Journal of Neuropathology \& Experimental Neurology. 2004;63(9):901-10. 
236. Nogawa S, Zhang F, Ross ME, ladecola C. Cyclo-oxygenase-2 gene expression in neurons contributes to ischemic brain damage. Journal of Neuroscience. 1997;17(8):2746-55.

237. ladecola C, Forster C, Nogawa S, Clark HB, Ross ME. Cyclooxygenase-2 immunoreactivity in the human brain following cerebral ischemia. Acta neuropathologica. 1999;98(1):9-14.

238. Sairanen T, Ristimäki A, Karjalainen-Lindsberg ML, Paetau A, Kaste M, Lindsberg PJ. Cyclooxygenase-2 is induced globally in infarcted human brain. Annals of neurology. 1998;43(6):738-47.

239. Topol EJ. Failing the public health-rofecoxib, Merck, and the FDA. New England Journal of Medicine. 2004;351(17):1707-9.

240. Kawano T, Anrather J, Zhou P, Park L, Wang G, Frys KA, et al. Prostaglandin E 2 EP1 receptors: downstream effectors of COX-2 neurotoxicity. Nature medicine. 2006;12(2):225

241. Hata AN, Breyer RM. Pharmacology and signaling of prostaglandin receptors: multiple roles in inflammation and immune modulation. Pharmacology \& therapeutics. 2004;103(2):147-66.

242. Ahmad AS, Saleem S, Ahmad M, Doré S. Prostaglandin EP1 receptor contributes to excitotoxicity and focal ischemic brain damage. Toxicological Sciences. 2005;89(1):265-70.

243. Zhou P, Qian L, Chou T, ladecola C. Neuroprotection by PGE2 receptor EP1 inhibition involves the PTEN/AKT pathway. Neurobiology of disease. 2008; 29(3):543-51.

244. Baeuerle PA, Henkel T. Function and activation of NF-kappaB in the immune system. Annual review of immunology. 1994;12(1):141-79.

245. Khan M, Jatana M, Elango C, Paintlia AS, Singh AK, Singh I. Cerebrovascular protection by various nitric oxide donors in rats after experimental stroke. Nitric oxide. 2006;15(2):114-24.

246. Harari OA, Liao JK. NF-KB and innate immunity in ischemic stroke. Annals of the New York Academy of Sciences. 2010;1207:32-40.

247. Herrmann O, Baumann B, de Lorenzi R, Muhammad S, Zhang W, Kleesiek J, et al. IKK mediates ischemia-induced neuronal death. Nat Med. 2005:11(12): $1322-9$

248. Fann DY-W, Lim Y-A, Cheng Y-L, Lok K-Z, Chunduri P, Baik S-H, et al. Evidence that NF-KB and MAPK signaling promotes NLRP inflammasome activation in neurons following ischemic stroke. Molecular neurobiology. 2018;(2):1082-1096. https://doi.org/10.1007/s12035-017-0394-9.

249. Kim EK, Choi EJ. Compromised MAPK signaling in human diseases: an update. Archives of toxicology. 2015;89(6):867-82.

250. Sun J, Nan G. The mitogen-activated protein kinase (MAPK) signaling pathway as a discovery target in stroke. Journal of Molecular Neuroscience. 2016:59(1):90-8

251. Roy Choudhury G, Ryou M-G, Poteet E, Wen Y, He R, Sun F, et al. Involvement of p38 MAPK in reactive astrogliosis induced by ischemic stroke. Brain research. 2014;1551:45-58.

252. Sims NR, Yew WP. Reactive astrogliosis in stroke: Contributions of astrocytes to recovery of neurological function. Neurochemistry international. 2017; 107:88-103.

253. Walton KM, DiRocco R, Bartlett BA, Koury E, Marcy VR, Jarvis B, et al. Activation of p38MAPK in microglia after ischemia. Journal of neurochemistry. 1998;70(4):1764-7.

254. Sugino T, Nozaki K, Takagi Y, Hattori I, Hashimoto N, Moriguchi T, et al. Activation of mitogen-activated protein kinases after transient forebrain ischemia in gerbil hippocampus. Journal of Neuroscience. 2000;20(12):4506-14.

255. Maddahi A, Kruse LS, Chen OW, Edvinsson L. The role of tumor necrosis factor-alpha and TNF-alpha receptors in cerebral arteries following cerebral ischemia in rat. Journal of neuroinflammation. 2011;8:107.

256. Maddahi A, Edvinsson L. Cerebral ischemia induces microvascular proinflammatory cytokine expression via the MEK/ERK pathway. Journal of neuroinflammation. 2010;7:14.

257. Tao X, Sun X, Yin L, Han X, Xu L, Qi Y, et al. Dioscin ameliorates cerebral ischemia/reperfusion injury through the downregulation of TLR4 signaling via HMGB-1 inhibition. Free Radic Biol Med. 2015;84:103-15.

258. Hayakawa K, Arai K, Lo EH. Role of ERK map kinase and CRM1 in IL1 beta-stimulated release of HMGB1 from cortical astrocytes. Glia. 2010; 58(8):1007-15.

259. Singh V, Roth S, Veltkamp R, Liesz A. HMGB1 as a key mediator of immune mechanisms in ischemic stroke. Antioxidants \& redox signaling. 2016;24(12): $635-51$

260. Štros M. HMGB proteins: interactions with DNA and chromatin. Biochimica et Biophysica Acta (BBA)-Gene Regulatory Mechanisms. 2010;1799(1):101-13.
261. Ueda T, Yoshida M. HMGB proteins and transcriptional regulation. Biochimica et Biophysica Acta (BBA)-Gene Regulatory Mechanisms. 2010; 1799(1):114-8

262. Kang R, Chen R, Zhang Q, Hou W, Wu S, Cao L, et al. HMGB1 in health and disease. Molecular aspects of medicine. 2014;40:1-116.

263. Martinotti S, Patrone M, Ranzato E. Emerging roles for HMGB1 protein in immunity, inflammation, and cancer. ImmunoTargets and therapy. 2015;4:101-9.

264. Magna M, Pisetsky DS. The role of HMGB1 in the pathogenesis of inflammatory and autoimmune diseases. Molecular medicine (Cambridge, Mass). 2014;20(1):138-46.

265. Yang H, Tracey KJ. Targeting HMGB1 in inflammation. Biochimica et Biophysica Acta (BBA)-Gene Regulatory Mechanisms. 2010;1799(1):149-56.

266. Yang H, Wang H, Czura CJ, Tracey KJ. The cytokine activity of HMGB1. Journal of leukocyte biology. 2005;78(1):1-8

267. Qiu J, Nishimura M, Wang Y, Sims JR, Qiu S, Savitz SI, et al. Early release of HMGB-1 from neurons after the onset of brain ischemia. J Cereb Blood Flow Metab. 2008;28(5):927-38.

268. Choi JY, Cui Y, Chowdhury ST, Kim BG. High-mobility group box-1 as an autocrine trophic factor in white matter stroke. Proc Natl Acad Sci U S A. 2017:114(25):E4987-e95.

269. Choi JY, Kim BG. Toll-like Receptor 2: A novel therapeutic target for ischemic white matter injury and oligodendrocyte death. Experimental neurobiology. 2017:26(4):186-94

270. Tsukagawa T, Katsumata R, Fujita M, Yasui K, Akhoon C, Ono K, et al. Elevated serum high-mobility group box-1 protein level is associated with poor functional outcome in ischemic stroke. J Stroke Cerebrovasc Dis. 2017; 26(10):2404-11.

271. Sadat-Hatamnezhad L, Tanomand A, Mahmoudi J, Sandoghchian Shotorbani S. Activation of toll-like receptors 2 by high-mobility group box 1 in monocytes from patients with ischemic stroke. Iranian Biomedical J. 2016:20(4):223-8.

272. Faraco G, Fossati S, Bianchi M, Patrone M, Pedrazzi M, Sparatore B, et al. High mobility group box 1 protein is released by neural cells upon different stresses and worsens ischemic neurodegeneration in vitro and in vivo. Journal of neurochemistry. 2007:103(2):590-603.

273. Sapojnikova N, Kartvelishvili T, Asatiani N, Zinkevich V, Kalandadze I, Gugutsidze D, et al. Correlation between MMP-9 and extracellular cytokine HMGB1 in prediction of human ischemic stroke outcome. Biochimica et biophysica acta. 2014;1842(9):1379-84.

274. Bierhaus A, Humpert PM, Morcos M, Wendt T, Chavakis T, Arnold B, et al. Understanding RAGE, the receptor for advanced glycation end products. Journal of molecular medicine. 2005:83(11):876-86.

275. Palumbo R, Galvez BG, Pusterla T, De Marchis F, Cossu G, Marcu KB, et al. Cells migrating to sites of tissue damage in response to the danger signal HMGB1 require NF-KB activation. J Cell Biol. 2007;179(1):33-40.

276. Miranda HV, Outeiro TF. The sour side of neurodegenerative disorders: the effects of protein glycation. The Journal of pathology. 2010;221(1):13-25.

277. Downes CE, Wong CH, Henley KJ, Guio-Aguilar PL, Zhang M, Ates R, et al. MyD88 is a critical regulator of hematopoietic cell-mediated neuroprotection seen after stroke. PloS one. 2013;8(3):e57948.

278. Kim J-B, Choi JS, Yu Y-M, Nam K, Piao C-S, Kim S-W, et al. HMGB1, a novel cytokine-like mediator linking acute neuronal death and delayed neuroinflammation in the postischemic brain. Journal of Neuroscience. 2006;26(24):6413-21.

279. Muhammad S, Barakat W, Stoyanov S, Murikinati S, Yang H, Tracey KJ, et al. The HMGB1 receptor RAGE mediates ischemic brain damage. Journal of Neuroscience. 2008;28(46):12023-31.

280. de Souza AW, Westra J, Limburg PC, Bijl M, Kallenberg CG. HMGB1 in vascular diseases: Its role in vascular inflammation and atherosclerosis. Autoimmunity reviews. 2012;11(12):909-17.

281. Kim JB, Sig Choi J, Yu YM, Nam K, Piao CS, Kim SW, et al. HMGB1, a novel cytokine-like mediator linking acute neuronal death and delayed neuroinflammation in the postischemic brain. J Neurosci. 2006;26(24): 6413-21.

282. Yang J, Huang C, Yang J, Jiang H, Ding J. Statins attenuate high mobility group box-1 protein induced vascular endothelial activation: a key role for TLR4/NF-kappaB signaling pathway. Molecular and cellular biochemistry. 2010;345(1-2):189-95.

283. Wilkins HM, Swerdlow RH. TNFa in cerebral ischemia: another stroke against you? Journal of neurochemistry. 2015;132(4):369-72. 
284. Bokhari FA, Shakoori TA, Butt A, Ghafoor F. TNF-alpha: a risk factor for ischemic stroke. JAMC. 2014;26(2):111-4

285. Gertz K, Kronenberg G, Kälin RE, Baldinger T, Werner C, Balkaya M, et al. Essential role of interleukin-6 in post-stroke angiogenesis. Brain. 2012;135(Pt 6):1964-80.

286. Roth J, Rummel C, Harré E-M, Voss T, Mütze J, Gerstberger R, et al. Is interleukin-6 the necessary pyrogenic cytokine? Journal of Thermal Biology. 2004;29(7):383-9.

287. Fahmi RM, Elsaid AF. Infarction size, interleukin-6, and their interaction are predictors of short-term stroke outcome in young Egyptian adults. J Stroke Cerebrovasc Dis. 2016;25(10):2475-81.

288. Becker KJ, Dankwa D, Lee R, Schulze J, Zierath D, Tanzi P, et al. Stroke, IL-1 ra, IL1RN, infection and outcome. Neurocritical care. 2014;21(1):140-6.

289. Murray KN, Parry-Jones AR, Allan SM. Interleukin-1 and acute brain injury. Front Cell Neurosci. 2015:9:18

290. Zaremba J, Losy J. Interleukin-12 in acute ischemic stroke patients. Folia Neuropathologica. 2006;44(1):59-66.

291. Nakamura K, Shichita T. Cellular and molecular mechanisms of sterile inflammation in ischaemic stroke. Journal of biochemistry. 2019;165(6): 459-64.

292. Clarkson BDS, Ling C, Shi Y, Harris MG, Rayasam A, Sun D, et al. T cellderived interleukin (IL)-21 promotes brain injury following stroke in mice. The Journal of Experimental Medicine. 2014;211(4):595-604.

293. Nayak AR, Kashyap RS, Kabra D, Purohit HJ, Taori GM, Daginawala HF. Time course of inflammatory cytokines in acute ischemic stroke patients and their relation to inter-alfa trypsin inhibitor heavy chain 4 and outcome. Annals of Indian Academy of Neurology. 2012;15(3):181-5.

294. Lakhan SE, Kirchgessner A, Tepper D, Leonard A. Matrix metalloproteinases and blood-brain barrier disruption in acute ischemic stroke. Frontiers in neurology. 2013;4:32

295. Chaturvedi M, Kaczmarek L. Mmp-9 inhibition: a therapeutic strategy in ischemic stroke. Molecular neurobiology. 2014;49(1):563-73.

296. Terpolilli NA, Moskowitz MA, Plesnila N. Nitric oxide: considerations for the treatment of ischemic stroke. J Cereb Blood Flow Metab. 2012;32(7):1332-46.

297. Xue Q, Yan Y, Zhang R, Xiong H. Regulation of iNOS on immune cells and its role in diseases. Int J Mol Sci. 2018;19(12). https://doi.org/10.3390/ ijms19123805.

298. Seifert HA, Collier LA, Chapman CB, Benkovic SA, Willing AE, Pennypacker KR. Pro-inflammatory interferon gamma signaling is directly associated with stroke induced neurodegeneration. J Neuroimmune Pharmacol. 2014;9(5):679-89.

299. Planas AM. Role of immune cells migrating to the ischemic brain. Stroke. 2018;49(9):2261-7.

300. Dobolyi A, Vincze C, Pál G, Lovas G. The neuroprotective functions of transforming growth factor beta proteins. International journal of molecular sciences. 2012;13(7):8219-58.

301. Garcia JM, Stillings SA, Leclerc JL, Phillips H, Edwards NJ, Robicsek SA, et al. Role of interleukin-10 in acute brain injuries. Frontiers in neurology. 2017;8:244.

302. Lambertsen KL, Finsen B, Clausen BH. Post-stroke inflammation-target or tool for therapy? Acta Neuropathologica. 2019;137(5):693-714.

303. Richard Seidu A, Sackey M, Su Z, Xu H. Pivotal neuroinflammatory and therapeutic role of high mobility group box 1 in ischemic stroke. Bioscience Reports. 2017;37(6):BSR20171104.

304. Tian X, Liu C, Shu Z, Chen G. Review: therapeutic targeting of HMGB1 in stroke. Current drug delivery. 2017;14(6):785-90.

305. Chen C, Chu SF, Liu DD, Zhang Z, Kong LL, Zhou X, et al. Chemokines play complex roles in cerebral ischemia. Neurochemistry international. 2018;112:146-58.

306. Amin M, Vakilian A, Mahmoodi MH, Hassanshahi G, Falahati-Pour SK, Dolatabadi MR, et al. Circulatory levels of $\mathrm{C}-\mathrm{X}$ - $\mathrm{C}$ motif chemokine ligands 1 , 9, and 10 are elevated in patients with ischemic stroke. The Eurasian journal of medicine. 2017;49(2):92-6.

307. Wang J, Gan Y, Han P, Yin J, Liu Q, Ghanian S, et al. Ischemia-induced neuronal cell death is mediated by chemokine receptor CX3CR1. Scientific Reports. 2018;8(1):556.

308. Rodrigo R, Fernandez-Gajardo R, Gutierrez R, Matamala JM, Carrasco R, Miranda-Merchak A, et al. Oxidative stress and pathophysiology of ischemic stroke: novel therapeutic opportunities. CNS \& neurological disorders drug targets. 2013;12(5):698-714.

309. Yang $J L$, Mukda S, Chen SD. Diverse roles of mitochondria in ischemic stroke. Redox biology. 2018;16:263-75.

310. Sun M-S, Jin H, Sun X, Huang S, Zhang F-L, Guo Z-N, et al. Free radical damage in ischemia-reperfusion injury: an obstacle in acute ischemic stroke after revascularization therapy. Oxidative medicine and cellular longevity. 2018;2018:17.

311. Narne P, Pandey V, Phanithi PB. Role of nitric oxide and hydrogen sulfide in ischemic stroke and the emergent epigenetic underpinnings. Molecular neurobiology. 2019;56(3):1749-69.

\section{Publisher's Note}

Springer Nature remains neutral with regard to jurisdictional claims in published maps and institutional affiliations.
Ready to submit your research? Choose BMC and benefit from:

- fast, convenient online submission

- thorough peer review by experienced researchers in your field

- rapid publication on acceptance

- support for research data, including large and complex data types

- gold Open Access which fosters wider collaboration and increased citations

- maximum visibility for your research: over $100 \mathrm{M}$ website views per year

At BMC, research is always in progress.

Learn more biomedcentral.com/submissions 